\title{
WestVirginiaUniversity
}

THE RESEARCH REPOSITORY @ WVU

Graduate Theses, Dissertations, and Problem Reports

2019

\section{Mandarin -guo Under Control: An Experimental Study}

Wei Zhou

wz0010@mix.wvu.edu

Follow this and additional works at: https://researchrepository.wvu.edu/etd

Part of the Syntax Commons

\section{Recommended Citation}

Zhou, Wei, "Mandarin -guo Under Control: An Experimental Study" (2019). Graduate Theses, Dissertations, and Problem Reports. 3764.

https://researchrepository.wvu.edu/etd/3764

This Thesis is protected by copyright and/or related rights. It has been brought to you by the The Research Repository @ WVU with permission from the rights-holder(s). You are free to use this Thesis in any way that is permitted by the copyright and related rights legislation that applies to your use. For other uses you must obtain permission from the rights-holder(s) directly, unless additional rights are indicated by a Creative Commons license in the record and/ or on the work itself. This Thesis has been accepted for inclusion in WVU Graduate Theses, Dissertations, and Problem Reports collection by an authorized administrator of The Research Repository @ WVU. For more information, please contact researchrepository@mail.wvu.edu. 
Mandarin -guo Under Control: An Experimental Study

Wei Zhou

Thesis submitted

to the Eberly College of Arts and Sciences

at West Virginia University

in partial fulfillment of the requirements for the degree of

Master of Arts in World Languages, Literatures, and Linguistics (Linguistics)

Department of World Languages, Literatures, and Linguistics

Sandra Stjepanovic, Ph.D., Chair

Jonah Katz, Ph.D.

Sergio Robles-Puente, Ph.D.

Department of World Languages, Literatures, and Linguistics

\author{
Morgantown, West Virginia
}

2019

Keywords: Mandarin -guo, aspect, control, actuality entailments

Copyright 2019 Wei Zhou 


\author{
ABSTRACT \\ Mandarin - guo Under Control: An Experimental Study
}

\begin{abstract}
Wei Zhou
This thesis examines the experiential aspectual marker - guo under control in Mandarin. The status of - guo under control has been a subject of controversy, involving two important theoretical questions. The first question concerns whether - guo under control is syntactically associated with the matrix verb or the embedded verb. The second question deals with whether, in terms of interpretive effects, -guo under control triggers actuality entailments. This thesis addresses the latter question through an interpretive judgment test conducted among 260 native Mandarin speakers. In the test, three control verbs (changshi 'try', guli 'encourage', and zuzhi 'oppose') were selected, each of which was combined with three respective aspectual conditions of -guo (no - guo, matrix -guo, and embedded - guo), yielding a total of nine sentence stimuli. Each sentence stimulus, accompanied by one of two contextual actualization conditions, was rated on a Likert Scale of 1-5. The corresponding ratings demonstrated how well each stimulus fit in the given contextual actualization condition. All elicited ratings were z-transformed by participant and analyzed with a mixed-effects regression model. The results show that there is no positive evidence that - guo under control triggers actuality entailments. Furthermore, these also suggest that interpretive effects may not be efficacious evidence for the existing debate about Mandarin control and non-control constructions in the literature.
\end{abstract}




\section{Acknowledgements}

I express my deepest gratitude to my advisor, Dr. Sandra Stjepanovic. She is knowledgeable and approachable, which has made working with her extremely rewarding and pleasant. Her comments are precise and thought-provoking, fostering the development of this thesis. I can still vividly remember when I began my graduate school search, she was the person who strengthened my conviction to come here, and still, I feel lucky to have made such a connection with her. Dr. Jonah Katz deserves enormous praise as well. He is generous sharing his time and expertise with his students, and I have benefited tremendously from meeting with him. He is a researcher and professor for whom I have great respect. Dr. Sergio Robles-Puente is also encouraging and supportive. He is always available to offer help when I am in need, and it has been a pleasure working with him.

I extend special gratification to Dr. Hannah Lin, who is a great inspiration and role model for me. I am grateful to her for providing me with valuable teaching experience as well as academic and life advice. She is a professor to whom I look up to, and a friend to whom I trust.

I feel grateful to Dr. Jonathan T. Fluharty-Jaidee, a finance professor at the University and a dear friend. As a linguistics undergraduate, he was a prior student of Dr. Stjepanovic. I thank him for his forthright critiques on this thesis and for his time in assisting me with data collection issues.

My friends and colleagues at the University have been of amazing support for me. I am thankful to them for going through all the joyful and less-entertaining moments with me.

I appreciate Dr. Marilyn Shea at the University of Maine at Farmington, who has been a loyal friend of mine. She is encouraging yet ready to offer frank and constructive critiques to me. I am indebted to her. 
My sincere appreciation goes to my friend Dr. Fred Bloom. He is someone to whom I turn to whenever I am in need. He is a great listener, with incredible patience. I am very grateful to him.

No matter where I am, Dr. Ming-Ming Pu at the University of Maine at Farmington always deserves mentioning. She is the person who introduced me to linguistics and inspired me to explore further. For that I will always be thankful.

Finally, I thank my family for their love and support. Without them, I would neve have made it this far. 
List of Abbreviations

\begin{tabular}{|c|c|c|}
\hline CL & $\ldots \ldots \ldots \ldots+\ldots, \ldots \ldots \ldots, \ldots$ & Classifier \\
\hline DUR & & Durative Aspect \\
\hline ERG & & Ergative \\
\hline EXP & $\ldots$. & Experiential Aspect \\
\hline IMPFV & & Imperfective Aspect \\
\hline NEG & & Negation \\
\hline PFV & & Perfective Aspect \\
\hline PROG & & Progressive Aspect \\
\hline PRS & $\ldots \ldots \ldots \ldots \ldots \ldots \ldots \ldots \ldots \ldots \ldots$ & Present \\
\hline PST & & Past \\
\hline SFP & & Sentence Final Particl \\
\hline
\end{tabular}




\section{Table of Contents}

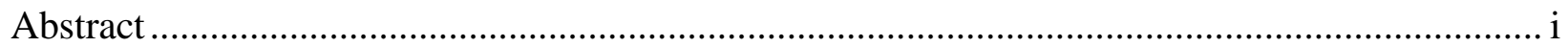

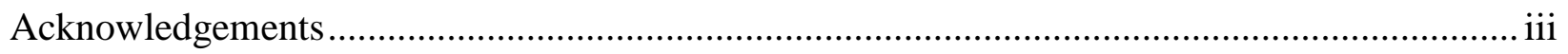

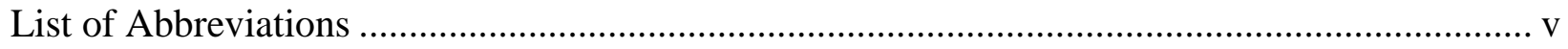

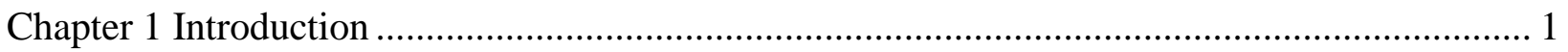

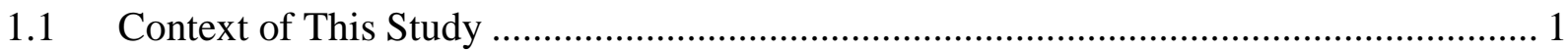

1.2 Status of Mandarin - guo Under Control....................................................................... 2

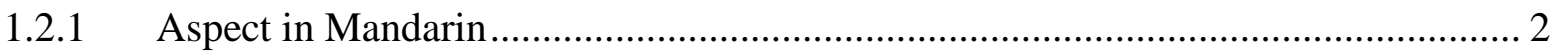

1.2.2 Control Constructions in Mandarin ...................................................................... 4

1.2.3 Mandarin Aspectual Markers Under Control ....................................................... 7

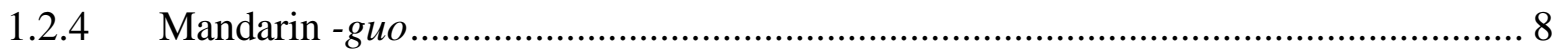

1.2.5 Mandarin -guo Under Control ........................................................................ 10

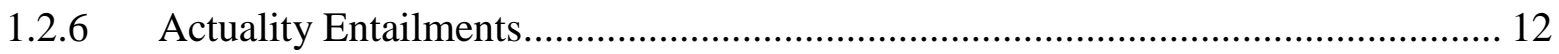

1.3 The Significance of Investigating Mandarin - guo Under Control ................................ 13

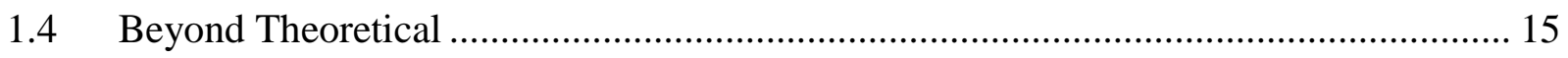

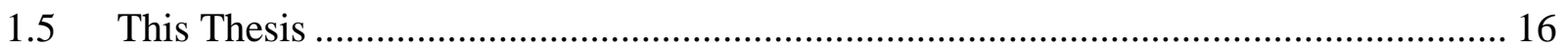

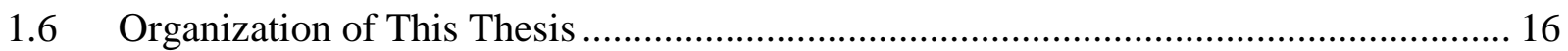

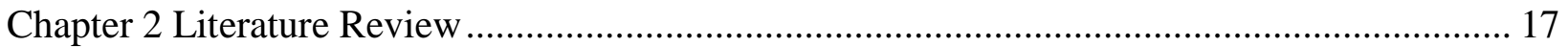

2.1 Debate about Control and Non-Control Constructions in Mandarin ............................ 17

2.1.1 Finite and Non-Finite Distinction ......................................................................... 17

2.1.2 Contra: Finite and Non-Finite Distinction ...................................................... 25

2.1.3 Mono-Clausal and Bi-Clausal Distinction ......................................................... 28

2.2 Mandarin -guo Under Control: A Matrix Analysis vs. An Embedded Analysis ........... 29

2.2.1 C.-T. J. Huang $(1982,1989)$ vs. Y. Huang $(1994)$............................................... 29

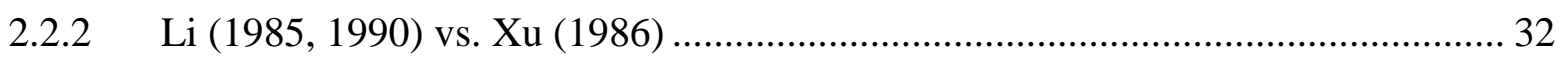

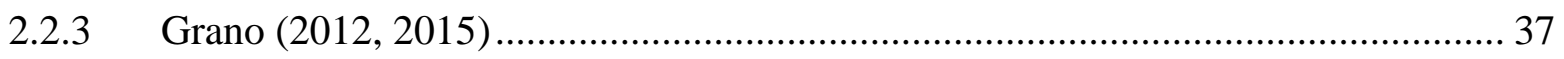

2.3 Grano and Zhang's (2018) Experimental Study ......................................................... 43

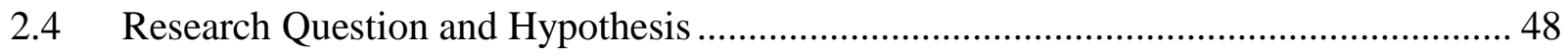

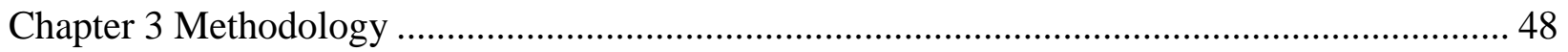

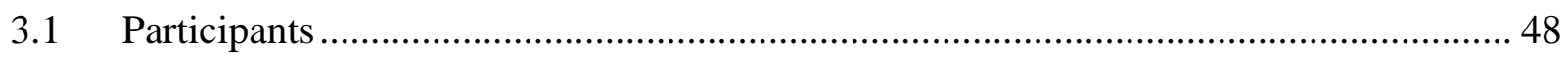

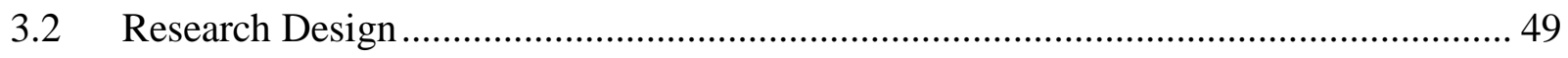

3.2.1 Sentence Stimuli ……………………………................................................. 49 
3.2.2 Contextual Conditions ............................................................................. 51

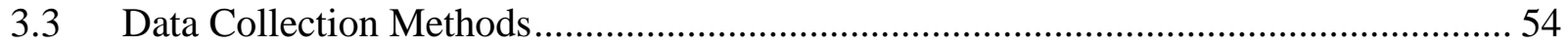

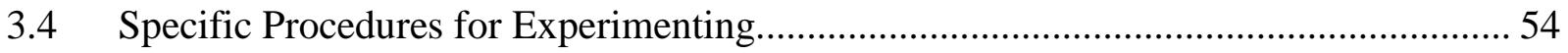

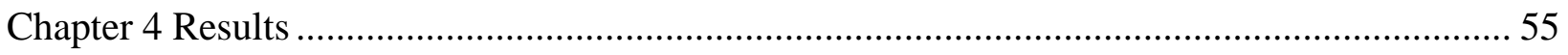

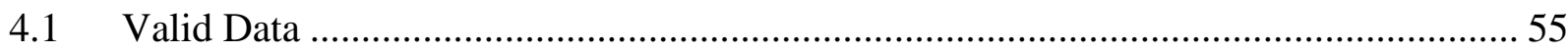

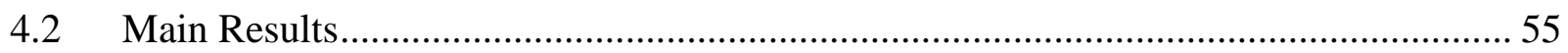

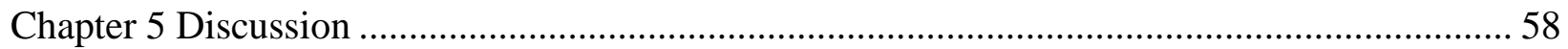

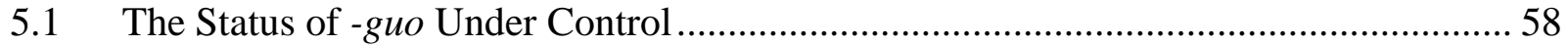

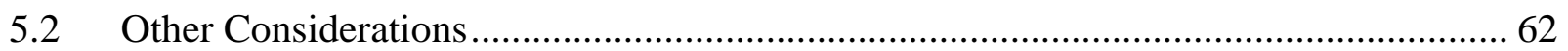

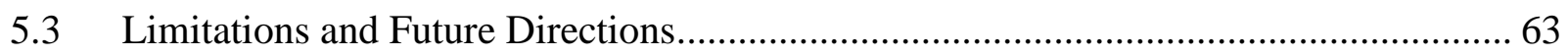

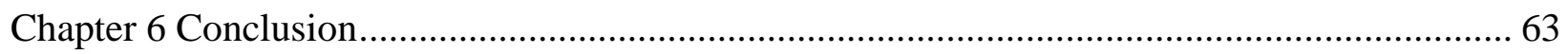

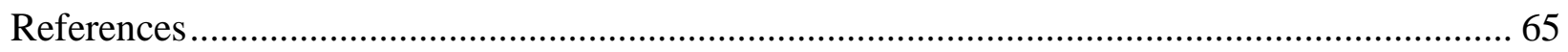




\section{Chapter 1 Introduction}

\subsection{Context of This Study}

The status of Mandarin experiential aspectual marker - guo in control complements has long been a subject of debate. This debate concerns two major questions: (a) Whether - guo under control is syntactically projected at the matrix level or the embedded level; and (b) whether - guo under control triggers actuality entailments. ${ }^{1}$ These two questions, meanwhile, connect closely to another debate in the literature as to whether Mandarin control and non-control structures are fundamentally different.

The primary purpose of this thesis is to experimentally explore question (b), the answer to which is crucial in at least two regards. First, such exploration informs us about the possible syntactic position of -guo under control. Second, this may shed light on the structural relationship between Mandarin control and non-control constructions.

This chapter outlines the state of affairs pertaining to the primary question of this thesis. Areas of consideration include Mandarin aspectual markers, control constructions, and aspectual markers under control. In this process, I also discuss the related properties of -guo, as well as the structure with - guo under control. These considerations then lead to discussion about actuality entailments. After that, I briefly discuss the conventional theoretical status of -guo under control, with consideration of a related experimental study, before introducing the experimental attempt taken up by this thesis. I close this chapter with an organizational overview of this thesis.

\footnotetext{
${ }^{1}$ Actuality entailments refer to the phenomenon where the actuality implications of events described by complements are not cancellable (Bhatt, 1998; Hacquard, 2006). Details regarding actuality entailments will be discussed in Section 1.2.6.
} 


\subsection{Status of Mandarin -guo Under Control}

\subsubsection{Aspect in Mandarin}

Mandarin Chinese (hereafter referred to as Mandarin) has no tense morphology but a rather rich aspectual system. ${ }^{2}$ Aspect is fundamentally different from tense in that tense, roughly defined, locates an event at a particular point on a timeline, whereas aspect describes a particular viewpoint or perspective tied to an event (Klein, 1994). For example, languages such as English and Dutch have an overt past tense, so English and Dutch verbs are grammatically marked for past tense. Consider the English sentence (1) and the Dutch sentence (2):

(1) John watched TV.

(2) Ik woonde in 1989 in Rotterdam.

I live.PST in 1989 in Rotterdam

'I lived in Rotterdam in 1989.'

(Sybesma, 2007, p. 582)

In (1), the verb watch is marked by the past tense morpheme -ed, indicating that the event of John watching TV took place before the time of speech. Similarly, the verb woon 'live' in (2) is marked by -de, communicating that the event, the subject's having lived in Rotterdam, occurred before the time of speech.

However, in Mandarin, verbs are not marked overtly for tense. For example:

\footnotetext{
${ }^{2}$ Although Mandarin does not have tense morphology, there is a heated debate in the literature as to whether Mandarin has covert tense. For affirmative view, see Tsang (1981), Li (1985, 1990), Simpson \& Wu (2002), Sybesma (2007), Tsai (2008), T.-H. J. Lin (2012, 2015), Sun (2014), N. Huang (2015), Law \& Ndayiragije (2017), among others. For negative view, refer to Klein (1994), Klein, Li, \& Hendriks (2000), Smith \& Erbaugh (2001), J.W. Lin $(2003,2006,2010)$, among others.
} 
(3) a. Ta xianzai jingchang gen Zhangsan liaotian.

He now often with Zhangsan chat

'He often chats with Zhangsan now.'

b. Ta guoqu jingchang gen Zhangsan liaotian.

He in the past often with Zhangsan chat

'He often chatted with Zhangsan in the past.'

In sentences (3a-b), the verb liaotian 'chat' remains in the same form regardless of the change of temporal adverbials. Notably, liaotian in (3b) is not overtly marked for tense despite clearly occurring in a past tense condition.

Although Mandarin verbs are not marked for tense, they are marked for aspect. Sentences (4a-b) illustrate how aspect is used in Mandarin.

(4) a. Zhangsan chi yu.

Zhangsan eat fish

'Zhangsan eats fish.'

b. Zhangsan zai-chi yu.

Zhangsan PROG-eat fish

'Zhangsan is/was/will be eating fish.'

In (4a), the verb $c h i$ 'eat' is not marked by any aspectual markers or sentence final particles that may potentially contribute to the temporal reference of the sentence; therefore, the sentence 
yields a default generic reading that Zhangsan eats fish regularly. In (4b), in contrast, the verb $c h i$ 'eat' is marked by the progressive aspectual marker zai-, which provides the event described by the predicate with a progressive reading. It thus conveys the information that Zhangsan is in the process of eating fish at some point.

There are several aspectual markers in Mandarin, including perfective -le, experiential guo, progressive zai-, durative -zhe, etc. (Li \& Thompson, 1981; J.-W. Lin, 2003). Since aspectual markers have been viewed as a useful device to locate the temporal reference of a sentence in Mandarin, it has received substantial attention in the literature (Chan, 1980; Li \& Thompson, 1981; Klein, Li, \& Hendriks, 2000; J.-W. Lin, 2003, 2006; Soh \& Kuo, 2005; Soh \& Gao, 2007; Yang, 2011; Soh, 2014; to mention only a few). However, previous work on aspectual markers has mostly focused on clauses with rather simple syntactic structures, and sentences with more complex structures have been much less discussed. This thesis attempts to fill this gap and centers upon Mandarin aspectual markers in control constructions. In the next subsection, I introduce control constructions and showcase some control examples in Mandarin.

\subsubsection{Control Constructions in Mandarin}

Within the Principles and Parameters Framework, control refers to a construction in which the overt matrix subject and the covert embedded subject share a dependent relation that is mediated through an empty pronominal element PRO (Bresnan, 1982; Hornstein, 1999, among others). For example, English sentences (5a-b) represent such constructions.

(5) a. John $n_{i}$ tried $\left[\mathrm{PRO}_{\mathrm{i}}\right.$ to do it].

b. $\mathrm{John}_{\mathrm{i}}$ persuaded Maryj $\left[\mathrm{PRO}_{\mathrm{j}}\right.$ to do it $]$. 
In (5a), the matrix subject, John, is co-indexed with the PRO in the subject position of the embedded clause, which constitutes a subject control structure. In (5b), the matrix object, Mary, is coreferential with the PRO in the embedded subject position, which forms an object control structure.

A more elaborate typology of control structures is given in Landau (1999, 2000). In his framework, control consists of obligatory control and non-obligatory control, each of which contains two subtypes: exhaustive control \& partial control within obligatory control and longdistance control \& arbitrary control within non-obligatory control. The typology of this is schematized in Figure 1.

\section{Figure 1 Classification of Control}

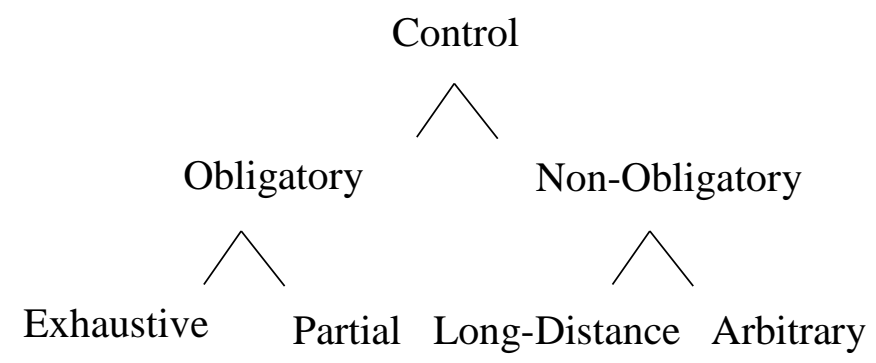

(Landau, 2000, p. 3)

Landau's $(1999,2000)$ definitions of different types/subtypes of control are:

(6) a. Obligatory Control (OC): The controller and the infinitive must be clausemates. All complement infinitivals fall into this category. 
a1. Exhaustive Control (EC): PRO must be identical to the controller.

a2. Partial Control (PC): PRO must include the controller.

b. Non-Obligatory Control (NOC): The infinitive need not have a clausemate controller. All subject and adjunct infinitivals belong to this category.

b1. Long-Distance Control (LD-Control): The controller and the infinitive are not clausemates.

b2. Arbitrary Control: PRO has no argument controller.

(Landau, 2000, p. 3)

In this thesis, the control constructions discussed are EC.

In the literature, the investigation of control is mainly influenced by the properties of control constructions in Germanic and Romance languages (Stiebels, 2007), and such constructions in non-Indo-European languages have, in contrast, been less investigated. For example, control in Mandarin has not received much attention in generative grammar (Grano, 2013); in fact, control occurs regularly in Mandarin. For example:

(7) a. Zhangsan ${ }_{i}$ dasuan $\mathrm{PRO}_{\mathrm{i}}$ xue yuyanxue.

Zhangsan plan learn linguistics

'Zhangsan plans to study linguistics.'

b. Lisi $i_{i}$ quan Zhangsan PRO $_{j}$ xue yuyanxue.

Lisi urge Zhangsan learn linguistics

'Lisi urges Zhangsan to study linguistics.' 
Like in English, the matrix subject of (7a), Zhangsan, is identified with the PRO in the embedded subject position (subject control), and the matrix object of (7b), Zhangsan, is identified with the PRO in the embedded subject position (object control).

In the sparse literature on control structures in Mandarin, the interaction between aspect and control has been, interestingly, paid a fair amount of attention by linguists (C.-T. J. Huang, 1982, 1989; Li, 1985, 1990; Xu, 1986; Tang, 1988; Cheng, 1989; Y. Huang, 1994; Hu, Pan, \& $\mathrm{Xu}, 2001$; Grano, 2012, 2015). I discuss some interesting facts about Mandarin aspectual markers under control in the next subsection.

\subsubsection{Mandarin Aspectual Markers Under Control}

In Mandarin, the progressive marker zai- is not allowed to occur in control complements (Grano, 2018). This is shown in (8). ${ }^{3}$

(8) *Wo quan ta zai-zuo fan.

I urge him PROG-cook meal

The experiential marker - guo and the perfective marker -le, on the other hand, are accepted in Mandarin control complements. This is illustrated in (9a-b).

(9) a. Wo quan ta zuo-guo fan.

I urge him cook-EXP meal 'I urged him to cook meals.'

\footnotetext{
${ }^{3}$ For an analysis of why the Mandarin progressive marker zai- cannot occur in control complements, see Grano
} (2018). 
b. Wo quan ta zuo-le fan.

I urge him cook-PFV meal

'I urged him to cook meals.'

Interestingly, sentences with aspectual markers under control, especially those with - guo under control like (9a), have been widely discussed examples in the literature of Mandarin control grammar. In the next two subsections, I introduce the properties of the aspectual marker guo and the characteristics of - guo under control respectively.

\subsubsection{Mandarin -guo}

Mandarin -guo is primarily considered as an experiential marker (Li \& Thompson, 1981; J.-W. Lin, 2003). In the aspectual system, experiential aspect designates that a certain event took place at least once from one point to another in time (Dahl, 1985). Crucially, Mandarin -guo expresses that an event has been, or has not been (if negated), experienced in relation to some reference time (Chao, 1968; Li \& Thompson, 1981). This experiential effect is illustrated in (10).

(10) Zhangsan qu-guo Yingguo.

Zhangsan go-EXP England

'Zhangsan has been to England.'

In (10), since the verb $q u$ 'go' is marked with the experiential marker - guo, the sentence expresses that Zhangsan has had the experience of going to England at least once in his whole life. 
In addition, Mandarin - guo contains a perfective viewpoint, which describes a realized situation whose final state no longer holds (Smith, 1991, 1994). This perfective effect is demonstrated in (11).

(11) Zhangsan chi-guo fan le. Zhangsan eat-PFV meal SFP 'Zhangsan ate/has eaten.'

In (11), the verb $c h i$ 'eat' is marked by -guo, indicating that the event of Zhangsan eating has already taken place by the time of speech. In this case, the perspective held on the event of eating does not necessarily (or primarily) focus on the fact that Zhangsan has had the experience of eating but that Zhangsan ate.

Since Mandarin -guo exhibits both an experiential and a perfective effect, i.e., an event denoting an experience is certainly a perfectivised event, and a perfectivised event can certainly be an experience of the subject's, it is also described as an experiential perfect marker (Dahl, 1985). ${ }^{4}$ However, it is also worth mentioning that -guo should not be equated to past tense; instead, it denotes relative anteriority notwithstanding the aktionsart of the sentence that hosts it (J.-W. Lin, 2003). In this thesis, for the ease of exposition, I simply refer to -guo as an experiential marker.

As mentioned previously, Mandarin - guo under control has drawn considerable attention in the literature. In the following subsection, I discuss the characteristics of -guo under control in Mandarin.

\footnotetext{
${ }^{4}$ According to Dahl, the experiential perfect marker exists in eight languages. These languages are: Chinese (Mandarin), Japanese, Javanese, Thai (Siamese), Sundanese, Indonesian, Ișẹkiri, and Sotho.
} 


\subsubsection{Mandarin -guo Under Control}

In Mandarin control constructions, when the experiential marker -guo occurs with the matrix predicate, it indicates that the matrix event described by the matrix predicate has been realized. For example:

(12) Wo qing-guo Zhangsan chi fan.

I invite-EXP Zhangsan eat meal

'I have invited Zhangsan to eat.'

In (12), the experiential marker - guo is attached to the matrix verb qing 'invite', giving the clause an interpretation that the action of inviting Zhangsan has been carried out; meanwhile, since there is no aspectual marker in the complement, the event of eating described by the complement predicate chi fan 'eat a meal' needs not have taken place.

However, when -guo occurs in a control complement, the interpretation of such a sentence seems to become somewhat puzzling. For example:

(13) Wo qing Zhangsan chi-guo fan.

I ask Zhangsan eat-EXP meal

'I have invited Zhangsan to eat.'

(Li, 1985, p. 36) 
In (13), the experiential marker - guo occurs with the complement verb chi 'eat'. Interestingly, the interpretation of this sentence has not been agreed upon in the literature. Some linguists argue that although -guo occurs in the embedded complement with the embedded predicate, it is realized non-locally as the matrix aspect. Thus, - guo under control does not give sentences like (13) an interpretation that the embedded event has taken place; rather, it only gives them an interpretation that the matrix event has occurred (Li, 1985, 1990; C.-T. J. Huang, 1989; Cheng, 1989; Grano, 2012, 2015). However, some other linguists hold the opposite opinion, which is that - guo in control complements is realized locally as the embedded aspect; hence, - $g$ uo under control provides sentences like (13) with an interpretation that the embedded event has already taken place (Xu, 1986; Tang, 1988; Y. Huang, 1994; Hu, Pan, \& Xu, 2001). This dispute reflects two major theoretical questions about - guo under control in Mandarin. The first question is that whether -guo is syntactically owned by the control complement or the matrix clause. These two possible syntactic projections of - guo are schematized in (14) and (15).

(14) Non-local realization of aspect

$[-$ guo $[\ldots$. Vmatrix ... [ . . Vembedded ... ] ] ]

(15) Local realization of aspect

$[\ldots$. Vmatrix ... [-guo $[\ldots$. . Vembedded ... ] ] ]

(Grano, 2013, p. 2) [Slightly modified]

The second question (i.e., whether it designates the embedded event has taken place) discussed by the linguists, according to Grano and Zhang (2018), refers to a phenomenon called actuality 
entailments, a term first introduced by Bhatt (1999). The next subsection discusses the notion of actuality entailments and explains how it applies to this - guo under control debate.

\subsubsection{Actuality Entailments}

The notion of actuality entailments was brought forth by Bhatt (1999) to refer to instances where the actuality implications (or propositions) of events described by complements

are not cancellable. ${ }^{5}$ For example, in Hindi, when an ability modal co-occurs with imperfective aspect, the actualization of the ability is not entailed; when it co-occurs with past perfective aspect, the actualization of the ability is entailed and irrefutable. Consider (16a-b).
(16) a. Yusuf havaii-jahaaz uraa sak-taa
hai/thaa
(lekin vo havaii-jahaaz
Yusuf air-ship
fly can-IMPFV
be.PRS/be.PST but he air-ship nahĩì uraa-taa hai/thaa.
NEG fly-IMPFV be.PRS/be.PST
'Yusuf is/was able to fly airplanes, but he doesn't/didn't fly airplanes.'
b. Yusuf havaii-jahaaz uraa sak-aa (*lekin us-ne havaii-jahaaz nahĩĩ uraa-yaa). Yusuf air-ship fly can-PFV but he-ERG air-ship NEG fly-PFV 'Yusuf could fly the airplane, but he didn't fly the airplane.'

(Bhatt, 1999, p. 176)

In (16a), the modal verb sak 'can' is marked for imperfective aspect, the proposition described by the first clause still holds true when followed by a clause asserting the non-actualization of the

\footnotetext{
${ }^{5}$ More discussions about actuality entailments can be found in Hacquard (2006).
} 
ability; however, in (16b), when the modal verb sak 'can' is marked for past perfective aspect, the proposition described by the first clause becomes unacceptable when followed by a clause postulating the non-actualization of the ability. This process represented in (16b), which involves a non-cancellable event actualization condition, is referred to as actuality entailments.

Based on the characteristics exhibited by the Hindi examples above, the previous question discussed in Section 1.2.5, i.e., whether Mandarin -guo under control indicates that the embedded event has occurred, can be reiterated as whether -guo under control triggers actuality entailments. That is, if -guo under control actualizes the embedded event and such an actualization cannot be canceled, it triggers actuality entailments.

Understanding -guo under control with respect to actuality entailments could make important contributions in at least two ways. From a language-specific view, understanding the status of -guo can provide evidence towards explicating the structures of control constructions in Mandarin. From a language-general perspective, it can contribute to the literature of control in natural language, in that it can shed light on how control constructions in Mandarin are similar to, or different from, those in other languages. That said, the upcoming subsection elaborates the significance of studying -guo in control complements.

\subsection{The Significance of Investigating Mandarin -guo Under Control}

The structural relationship between control and non-control constructions in Mandarin is a subject of debate in Mandarin. One of the central controversies lies in whether control and noncontrol constructions are syntactically different.

One argument for control and non-control structures being fundamentally different is based on the assumption that they exhibit a finite/non-finite distinction: Control complement 
clauses are assumed to be non-finite and non-control complement clauses are assumed to be finite. Linguists who support this view include Huang (1982, 1989), Li (1985, 1990), Ernst (1994), C.-C. J. Tang (1990), T.-C. Tang (2000), T.-H. J. Lin (2011), Zhang (2016), N. Huang (2018), among others. Another argument for the structural difference claim is credited to Grano (2012, 2015), who argues that the syntactic differences between control and non-control constructions may result from a mono-clausal/bi-clausal distinction, not finiteness.

Another group of linguists, however, does not entertain the view that control and noncontrol constructions have fundamental structural differences. They usually argue for their position by providing counterexamples to challenge the proposed frameworks, which rely on the systematic syntactic properties of Mandarin control constructions. These linguists include $\mathrm{Xu}$ (1986), Y. Huang (1994), Pan, Hu, \& Xu (2001), J.-W. Lin (2010), among others. A more detailed review of the arguments from both sides of this debate is provided in Chapter 2.

In this heated debate of Mandarin control and non-control constructions, the status of the experiential marker - guo under control has, interestingly, been used by both sides as evidence for their proposals. Among these discussions, as pointed out in Section 1.1, there are two most prominent questions: the syntactic position of -guo under control and the interpretive effects on event actualization in sentences containing -guo under control. More interestingly, the diverging answers to this question by the two groups of linguists seem to parallel positions on the potential differences between control and non-control structures: Those who believe that control and noncontrol structures are different claim - guo under control to be projected higher at the matrix level, and those who believe in no systematic difference (e.g., in finiteness) claim -guo under control to be projected locally at the embedded level. Hereinto, it becomes interesting to study guo under control, not only due to this particular debate of whether control and non-control 
constructions are syntactically and semantically different, but also due to the contribution it can make to the inquiry into how control resembles and varies cross-linguistically. Recently, investigation of - guo under control has extended into the experimental field. The next subsection briefly summarizes a recent experimental examination of -guo under control.

\subsection{Beyond Theoretical}

Given that linguists do not agree upon the status of Mandarin -guo under control in the theoretical domain, Grano and Zhang (2018) approached this problem through an experimental lens; specifically, they examined whether -guo under control in Mandarin sentences, such as (17), triggers actuality entailments.

(17) Wo quan ta qu-guo Yingguo.

I urge him go-EXP England

'I urged him to go to England.'

In their experiment, control sentence stimuli were constructed using the object control verb quan 'urge' combined with either matrix -guo, embedded -guo or no -guo (zero aspect). The acceptability of each stimulus was judged based on a "Happen" context (wherein the embedded event is actualized) and a "Fail" context (wherein the embedded event is not actualized) by 36 native speakers on a scale of 1-5, 5 being most acceptable. Their data indicated that -guo under control does not yield actuality entailments, which further suggested that -guo under control instantiates non-local realization of the matrix aspect. 


\subsection{This Thesis}

This study builds on Grano and Zhang's (2018) study and aims to gain a more comprehensive understanding of the question as to whether - guo under control gives rise to actuality entailments. Crucially, this study extends the empirical database that informs us about the status of - guo under control by including both subject control and object control verbs, increasing the experimental sample size and number of observations, and refining the former study's contextual actualization conditions. More details regarding how this study extends the former study are discussed in Chapter 2.

\subsection{Organization of This Thesis}

This thesis is organized in the following ways. In Chapter 2, I first review the debate regarding control and non-control constructions in Mandarin. Then, I summarize the literature on the status of - guo under control and explain its relevance for the debate about control and noncontrol structures. Finally, I review Grano and Zhang's (2018) experiment about -guo under control in detail and propose the research question and hypothesis of this study. In Chapter 3, I discuss the methodology of this study, including the participants, the design of the research, the data collection instruments and methods, and the specific procedures for experimenting. In Chapter 4, I present and analyze the quantitative data and results. In Chapter 5, I discuss the experimental results and their implications with respect to the status of - guo under control, as well as the debate about control and non-control constructions in Mandarin. I also pinpoint some other interesting considerations following from the results. In Chapter 6, I conclude this thesis. 


\section{Chapter 2 Literature Review}

\subsection{Debate about Control and Non-Control Constructions in Mandarin}

There has been a heated debate about the relationship between control and non-control constructions in Mandarin. The central theme of the debate lies in whether control and noncontrol constructions show systematic syntactic differences. For linguists who argue that control and non-control constructions are structurally different, their views can generally be traced in two lines: The first line lies in finiteness; the second line is clausal structure. For linguists who hold the opposite view, they typically provide counterexamples to undermine the theory proposed by the other group of linguists.

\subsubsection{Finite and Non-Finite Distinction}

A great deal of existing work argues that control and non-control constructions in Mandarin exhibit consistent differences in their finiteness. More specifically, some linguists argue that control complements are non-finite and non-control complement clauses are finite. For example, C.-T. J. Huang $(1982,1989)$ argued that there is a rather systematic way to distinguish between finite and non-finite clauses, which is the presence of AUX (or INFL). AUX can host elements such as aspectual markers or modal verbs. According to C.-T. J. Huang, finite clauses, which are non-control clauses, contain an AUX and thus allow the potential occurrence of an AUX element, viz., an aspectual marker or a modal verb. For example, both sentences in (19) contain an AUX: The AUX in (19a) is realized as the perfective aspectual marker -le, while that in (19b) is realized as the modal verb hui. In (20), the AUX is present but covert. ${ }^{6}$

\footnotetext{
${ }^{6}$ The embedded clause in (20) contains a covert AUX based on the rule in (22), which is stated later in this subsection. Besides, Huang assumed that for clauses exhibiting a habitual, such as (20), the habitual has the form of a zero-morpheme.
} 
(19) a. Zhangsan shuo [(ta) lai le].

Zhangsan say he come PFV

'Zhangsan said that (he) came.'

b. Zhangsan xiangxin [(ta) hui lai].

Zhangsan believe he will come

'Zhangsan believes that (he) will come.'

(20) Zhangsan shuo [(ta) meitian lai].

Zhangsan say he every-day come

'Zhangsan said that (he) comes/came every day.'

(C.-T. J. Huang, 1989, p. 188-89)

However, non-finite control complements do not contain an AUX and therefore cannot allow an AUX element. This is shown below, in which the presence of the durative marker $-z a i$ in $(21 \mathrm{~b})$ and the modal verb hui in (21c) causes ungrammaticality.

(21) a. Wo bi Lisi [e lai]

I force Lisi come

'I forced Lisi to come.'

b. ${ }^{*}$ Wo bi Lisi [e lai zhe].

I force Lisi come DUR

c. *Wo bi Lisi [e hui lai].

I force Lisi will come

(C.-T. J. Huang, 1989, p. 189) 
Based on (19)-(21), C.-T. J. Huang claimed that an embedded clause under a control verb such as $b i$ 'pressure' and quan 'urge' can never take any AUX elements, while an embedded clause under a verb such as shuo 'say' and xiangxin 'believe' can take an element of AUX, although it need not take an AUX overtly. ${ }^{7}$

In addition, C.-T. J. Huang argued that there is a systematic correlation between the possibility of having an AUX element and the possibility of having a lexical subject in a clause. This correlation can be stated in terms of the unidirectional implication in (22). In his words:

(22) If the subject of a clause is obligatorily null, then the clause cannot contain an element of AUX.

Evidence for (22) rests on the fact that the embedded subject under control must be null. Because of that, the presence of a lexical embedded subject in such clauses will trigger ungrammaticality. Sentences (23) and (24) illustrate this.

(23) a. Wo zhunbei [PRO mingtian lai].

I prepare tomorrow come

'I expect to come tomorrow.'

b. *Wo zhunbei [wo mingtian lai].

I prepare I tomorrow come

\footnotetext{
${ }^{7}$ There are apparent counterexamples to this point. For example, in the case of (21b), the experiential marker - guo and the perfective marker -le can instead occur in the complement of the control verb $b i$ 'force'. C.-T. J. Huang argued that these cannot be real counterexamples to his AUX argument. The reason for that will be discussed in Section 2.2.1.
} 
(24) a. Wo quan Zhangsan [PRO bu mai zhe-ben shu].

I urge Zhangsan NEG buy this-CL book

'I urged Zhangsan not to buy this book.'

b. *Wo quan Zhangsan [ta bu mai zhe-ben shu].

I urge Zhangsan he NEG buy this-CL book

(C.-T. J. Huang, 1982, p. 350-51)

For clauses under control verbs, C.-T. J. Huang claimed that they are non-finite without AUX. Considering his analysis within the Government and Binding Theory (Chomsky 1981), C.-T. J. Huang (1982) proposed that the embedded subject of such clauses is ungoverned and therefore must be obligatorily null to avoid a violation of the Case Filter, which required all overt NPs to have Case assigned under government [cf. (21), (23) and (24)]. ${ }^{8}$ On the other hand, the subject of a clause containing an AUX can be either lexical or null [cf. (19) and (20)]. A lexical subject is expected because AUX governs the subject and allows it to satisfy the Case Filter.

In support of a finite and non-finite distinction, $\operatorname{Li}(1985,1990)$ provided two other pieces of evidence. Li started with the observation that as in many other languages, Mandarin has different types of matrix clauses: tell-type matrix verbs ${ }^{9}$ and persuade-type matrix verbs. One criterion that distinguishes these types of predicates and the types of embedded clauses they take is Negative Polarity Items (NPI) licensing. Renhe 'any' is an NPI in Mandarin. Sentences in (25) show that renhe can only be used in conditionals (25a) and negatives (25b), not declaratives (25c).

\footnotetext{
${ }^{8}$ According to Huang, it is the case unless in some instances where the subject is allowed to be governed from outside of the embedded clause.

${ }^{9}$ In some cases, expect-type verbs (Kuno, 1974), or believe-type verbs (Franks \& Hornstein, 1992; Noël, 2002), are used to refer to the same category of verbs.
} 
(25) a. Ni xihuan renhe dongxi jiu gaosu wo.

you like any thing then tell me

'(If) you like anything, then tell me.'

b. Ta bu xihuan renhe dongxi.

He NEG like any thing

'He does not like anything.'

c. *Ta xihuan renhe dongxi.

he like any thing

(Li, 1990, p. 20)

According to Li, the matrix negation can license an embedded NPI in sentences containing persuade-type matrix verbs, but not tell-type matrix verbs. For example, (26a) contains a tell-type verb zhidao 'know', and the matrix negation marker bu cannot license the embedded NPI renhe 'any'; on the other hand, (26b) contains a persuade-type verb jianyi 'advise', and the matrix negation marker $b u$ can license the embedded NPI renhe.

(26) a. *Lisi bu zhidao Zhangsan [xue renhe dongxi]. Lisi NEG know Zhangsan learn any thing Intended: 'Lisi does not know that Zhangsan studies anything.'

b. Lisi bu jianyi Zhangsan [xue renhe dongxi].

Lisi NEG advise Zhangsan learn any thing 'Lisi does not advise Zhangsan to study anything.' 
In addition to that, when the embedded NPI renhe 'any' occurs in clauses containing telltype verbs, it must be licensed by a negation within the same clause such as in (27a), not a negation in a different clause such as in (27b), which was also shown in (26a).

(27) a. Zhangsan gaosu-guo ta Lisi mei zuo renhe shi. Zhangsan tell-EXP her Lisi NEG make any thing 'Zhangsan have not told her that Lisi did anything.'

b. *Zhangsan mei gaosu-guo ta Lisi zuo renhe shi. Zhangsan NEG tell-EXP her Lisi do any thing Intended: 'Zhangsan have not told her that Lisi did anything.'

However, when the embedded NPI renhe 'any' occurs in persuade-type clauses, it can be licensed by a negation in a different clause, as in (28a) [cf. (27b)]. Moreover, renhe can even be separated from the licensing negation by more than one clause, as in (28b). ${ }^{10}$

(28) a. Zhangsan mei quan-guo Lisi zuo renhe shi. Zhangsan NEG persuade-EXP Lisi do any thing 'Zhangsan have not persuaded Lisi to do anything.'

b. Wo mei jiao ta pai ni qu quan tamen zuo renhe shiqing.

I NEG ask him send you go persuade them do any thing 'I have not asked him to send you to persuade them to do anything.'

(Li, 1990, p. 21)

${ }^{10}$ Although Li did not specify whether the intervening clause(s) can be finite or not. 
Thus far, it seems that the NPI licensing test can be relied on to differentiate clauses with telltype verbs and those with persuade-type verbs in Mandarin. Considering the cross-linguistic fact that clauses with tell-type verbs are typically finite and clauses with persuade-type verbs are usually non-finite, $\mathrm{Li}$ came to the initial conclusion that Mandarin also exhibits a finite/non-finite distinction between tell-type and persuade-type clauses. However, it is not clear, based on $\mathrm{Li}$, why finiteness should be the distinguishing criterion for control and noncontrol structures, but not something else, such as a mono-clausal and bi-clausal distinction.

The other piece of evidence, according to $\mathrm{Li}$, lies in the potential for clauses to allow tense markers: Finite clauses allow tense markers and non-finite clauses do not. She adopted Tsang's (1981) proposal that hui 'will, can' and yao 'will, want' can be tense markers in Mandarin. ${ }^{11}$ Notably, hui is ambiguous in some cases. It can operate both as a tense marker denoting future and as a modal denoting ability (similar to can in English). For example, Mandarin sentence (29) has two English counterparts, and hui under Interpretation 1 is a modal, while hui under Interpretation 2 is a tense marker.

(29) Ta hui kai che he drive car 'He can drive.' —Interpretation 1 'He will drive.' - Interpretation 2

\footnotetext{
${ }^{11}$ This implies Li's assumption about the existence of overt tense in Mandarin, as also indicated in footnote 2.
} 
With this in mind, consider sentences (30a-b), which show how hui behaves in control and non-control complement clauses and how it can be used to distinguish these two types of complement clauses.

(30) a. Wo zhidao ta hui kan yingwen dianying.

I know he watch English movie

'I know he can watch English movies.' - Interpretation 1

'I know he will watch English movies.' —-Interpretation 2

b. *Wo bi ta hui kan yingwen dianying.

I pressure he watch English movie

Based on $\mathrm{Li}$, given that (30b) is ruled out, it must be that the embedded clause in it is non-finite since non-finite clauses allow the presence of tense markers. More precisely, the reason why hui is unacceptable in (30b) is because neither of hui's meanings can play a part: Hui as a tense marker is not possible, because the embedded clause is non-finite; it cannot be used as a modal due to its semantic incompatibility with the matrix predicate: An ability cannot be pressured. In contrast, (30a) is compatible with both hui's meanings, resulting in two interpretations. Crucially, when functioning as a tense marker, hui can occur in the embedded clause, giving rise to Interpretation 2 , because the clause is finite.

In the literature, one can find similar proposals in which control complement clauses are argued to be non-finite and non-control clauses to be finite, e.g., Ernst (1994), C.-C. J. Tang (1990), T.-C. Tang (2000), T.-H. J. Lin (2011), Zhang (2016), Grano (2017), N. Huang (2018), among others. However, these proposals are refuted in a group of other studies, in which counterexamples 
are provided to argue against the existence of a finite/non-finite distinction in Mandarin. These studies include Xu (1986), Tang (1988), Y. Huang (1994), Hu et al. (2001), J.-W. Lin (2010), among others. In the next subsection, I review the major arguments proposed by this group.

\subsubsection{Contra: Finite and Non-Finite Distinction}

In this subsection, I review some counterarguments to the proposals discussed in the previous subsection. More specifically, these counterarguments target C.-T. J. Huang's proposal about AUX and Li's NPI licensing and tense marker arguments.

For example, Hu at al. (2001) challenged C.-T. J. Huang's (1989) argument about AUX, whose presence is assumed to be only found in finite clauses. Recall that the evidence C.-T. J. Huang provided for the existence of AUX in clauses involves two assumptions: the potential to allow aspectual markers/modals and the potential to host lexical subjects. With respect to the latter assumption, $\mathrm{Hu}$ et al. argued that under specific circumstances, though rare, the subject of a complement clause of what seems to be a control predicate, can be lexicalized. For example, when some adverbial phrases occur between the matrix predicates zhunbei 'prepare' and quan 'urge' and the embedded predicates, a lexical subject is possible in the embedded subject position. Consider (31a-b) [cf. (23b) and (24b)].

(31) a. Wo zhunbei [mingtian xiawu tian hei yihou wo yi-ge ren lai]. I prepare tomorrow afternoon sky dark after I one-CL person come 'I plan to come alone tomorrow afternoon after it gets dark.' 
b. Wo quan Zhangsan [ruguo mei you ren mai zhe-ben shu, ta ye bu yao mai]. I urge Zhangsan if no have person buy this-CL book he also NEG will buy 'I urged Zhangsan not to buy this book if no one bought it.'

(Hu et al., 2001, p. 1131)

Based on (31a-b), Hu et al. concluded that the constraint on the occurrence of a lexical subject of the assumed nonfinite clauses is not restrictive since it can be loosened in some cases. ${ }^{12}$

C.-T. J. Huang's other assumption, which is about a clause's potential to host aspectual markers and modals, is also challenged by some linguists. However, I elaborate on arguments pertinent to this dispute later in Section 2.2 since they concern the core issues this thesis examines.

Besides, Hu et al. (2001) also argued that both of Li's $(1985,1990)$ distinguishing criteria for finiteness, the NPI licensing argument and the tense marker argument, are invalid. For instance, while Li claimed the embedded NPI renhe 'any' cannot be licensed by the matrix negation in socalled finite clauses, Hu et al. provided counterexamples in which renhe 'any' is licensed by the matrix negation in such assumed finite clauses. Such examples are illustrated in (32). ${ }^{13}$

\footnotetext{
12 The matrix verb in such cases may, in fact, be ambiguous between taking a non-finite and finite complement, so these may be finite clauses with a null AUX, which allows for C.-T. J. Huang's (1989) condition on lexical subjects in non-finite clauses to still hold. For example, the verb plan and urge, the English counterparts of the matrix verbs zhunbei and quan in (31), may take both a non-finite and finite complement. This is shown in (A) - (D).

(A) I plan that after years of working for my company, I can start my own business].

(B) I plan to come alone after it gets dark].

(C) I urged them that if no one buys it, I will buy it].

(D) I urged them to buy it.

${ }^{13}$ These counterexamples may not be convincing unless the issue of long-distance licensing of NPI renhe 'any' with respect to tingshuo 'hear' is dealt with. In English, even with some non-NEG raising predicate (i.e., predicates that normally do not allow for NPIs in their complement clauses to be licensed by matrix negation), long-distance licensing of 'any' is allowed, as shown in Gajewski (2005). For example, a negation above a non-NEG raising predicate (e.g., claim, regret, know) can license any/ever but not until/in years. See (A) and (B).
} 
(32) a. Wo meiyou tingshuo [Zhangsan xihuan-shang renhe guniang].

I not-have hear Zhangsan begin-to-like any girl

'I did not hear that Zhangsan had fallen in love with any girl.'

b. Wo meiyou tingshuo [Zhangsan da-guo renhe ren].

I not-have hear Zhangsan beat-EXP any person

'I did not hear that Zhangsan had beaten anyone.'

(Hu et al., 2001, p. 1128)

In (32a-b), the complements of both sentences containing the matrix verb tingshuo 'hear', should be finite based on Li's arguments; however, renhe in both complements can be licensed by a matrix negation.

In terms of the tense marker test, Hu et al. also gave counterexamples such as that in (33), in which the assumed tense marker yao 'will, want' occurs in the control complement.
(33) Wo bi
ta [yao shang xue].
I pressure him
go school
'I pressure him to go to school.'

\begin{abstract}
(A) a. Bill did not claim/regret/know that Mary had ever left the country.
b. Mary did not claim/regret/know that Bill had seen anything unusual.

(B) a. *Bill did not claim/regret/know that Mary would arrive until tomorrow.

b. *Mary did not claim/regret/know that Bill had left the country in years.
\end{abstract}

This contrasts with negated NEG raising predicates which license until/in years as well as any/ever. See (C) and (D).

(C) a. Bill did not think that Mary had ever left the country.

b. Mary did not believe that Bill had seen anything unusual.

(D) a. Bill does not think Mary will leave until tomorrow.

b. Mary does not believe Bill has left the country in years.

Therefore, for (32a-b) to be convincing, further evidence regarding the status of tingshuo 'hear' with respect to longdistance licensing of renhe 'any' is needed. 
The complement clause in (33) should be non-finite according to Li's tense marker criterion, but the tense marker yao can occur with the complement predicate without issue. Because of that, $\mathrm{Hu}$ et al. concluded that there is no systematic evidence for a finite/non-finite distinction in Mandarin.

\subsubsection{Mono-Clausal and Bi-Clausal Distinction}

Besides finiteness, the second line of arguments for structural differences between control and non-control constructions in Mandarin is grounded in the matter of clausal complexity. For example, Grano $(2012,2015)$ argued that compared to a finite/non-finite distinction, resorting to a monoclausal/biclausal distinction may be a better solution to accounting for the structural differences between control and non-control constructions. Specifically, according to Grano, exhaustive control predicates take $v \mathrm{P}$ complements that are smaller than a $\mathrm{CP}$. One compelling piece of evidence Grano provided for this proposal lies in data containing - guo and -le under control. I elaborate on these arguments later in Section 2.2.3.

Thus far, we have seen that the debate about the status of control and non-control structures in Mandarin mainly concerns the question as to whether or not control and non-control constructions are structurally different. Most scholars with the affirmative view propose a finite/non-finite distinction to account for these structural differences, whereas Grano (2012, 2015) proposes a mono-clausal/bi-clausal distinction. Scholars with the negative view, on the other hand, provide counterexamples to prove that there is no such a systematic distinction. Interestingly, in the debate on the relationship between control and non-control structures, the status of the experiential marker - guo under control has been used as evidence by scholars from 
both sides. What is so notable about - guo under control that draws such considerable attention?

In the next subsection, I expand on -guo with respect to control and non-control constructions in Mandarin.

\subsection{Mandarin -guo Under Control: A Matrix Analysis vs. An Embedded Analysis}

\subsubsection{C.-T. J. Huang (1982, 1989) vs. Y. Huang (1994)}

C.-T. J. Huang (1989) noted there are some apparent examples that appear to contradict his AUX [or INFL (1982)] argument discussed above. For example, aspectual markers can often be found in control complements. See (34a-b).

(34) a. Wo bi ta qu-le nali.

I pressure him go-PFV there

'I pressured him to go there.'

b. Wo bi ta qu-guo nali.

I pressure him go-EXP there

'I pressured him to go there.'

C.-T. J. Huang (1989) argued that in examples like (34a-b), although the aspectual markers -le and -guo under control seem to occur with the embedded verb on the surface, they are "better construed with the matrix verb (rather, with the entire sequence including the upper and the lower verb) rather than with the embedded verb.” The evidence for this claim, according to C.-T. J. Huang, rests on how negation operates in such sentences. For example, when (34a) is negated, the perfective marker you, which is a suppletive form of -le, must 
precede the matrix verb, as demonstrated in (35a); you cannot be found with the embedded clause, as shown in (35b).

\section{(35) a. Wo mei you bi ta qu nali. \\ I NEG PFV pressure him go there \\ 'I did not pressure him to go there.' \\ b. Wo bi ta mei you qu nali. \\ I pressure him NEG PFV go there}

Sentences (35a-b), along with (34a-b), raise two questions. First, why are aspectual markers such as -le and -guo attached to the embedded verb if they are better analyzed with the matrix one? Second, how does the fact that you must precede the matrix verb in a negative sentence support a matrix analysis? To address these questions, C.-T. J. Huang adopted A. Li's (1985) and M. Li's (1985) respective proposals that the V-NP-V sequence in control sentences should be treated as a complex verb. ${ }^{14}$ For the first question, he suggested that the aspectual markers

\footnotetext{
${ }^{14}$ A. Li (1985) argued that the evidence that a V-NP-V sequence is a complex verb lies in the fact that the object NP in the sequence cannot be an empty category, or it violates Lexical Integrity Hypothesis. This is shown in (A) and (B), in which extracting the object NP, Lisi, in (A) causes ungrammaticality, which is shown in (B).
(A) Wo bi Lisi mai-le liang-ben shu.
I pressure Lisi buy-PFV two-CL book 'I forced Lisi to buy two books.'
Lisi I pressure buy-PFV two-CL book

(B) *Lisi, wo bi $t$ mai-le liang-ben shu.

M. Li (1985) argued so by noting the fact that passivization, a process involving a clause-bounded constraint, permits long-distance extraction in sentences containing a V-NP-V sequence. For example, in (C), pai ren zhuazou, which can be literally translated to 'sent-someone-to-arrest', is a V-NP-V sequence, and when (C) is passivized, the sequence pai ren zhuazou remains as one component, a complex verb.

(C) Wo pai ren zhuazou-le Zhangsan.

I send someone arrest-PFV Zhangsan

'I sent someone to arrest Zhangsan.'

(D) Zhangsan bei wo pai ren zhuazou-le.
} 
such as -le and -guo in (34a-b) are base-generated in the same AUX position as you, which sits above the matrix predicate, as explained above. However, since they are verbal suffixes, they attach to the whole complex verb, giving an appearance that they occur with the embedded verb. The second question, following C.-T. J. Huang's theory, can be explained as that in a negative sentence, the position of you reveals the position of AUX because you is not a suffix. AUX occurs above the matrix verb only. Based on these, C.-T. J. Huang concluded that aspectual markers such as -le and -guo under control are associated with the matrix predicate underlyingly, even in cases where they appear with the embedded one on the surface, as in (34a-b) above.

However, Y. Huang (1994) challenged C.-T. J. Huang's (1989) negation argument by providing counterexamples. First, countering C.-T. J. Huang's case that negation and aspectual information (in this case you) must precede the matrix verb in the negative output of a control sentence, Y. Huang argued that negation and aspectual marking can co-occur with the embedded verb in cases where only the embedded verb needs to be negated. An example of that is illustrated in (36).

(36) Wo quan ta bu yao mai-le che.

I urge he NEG will sell-PFV car

'I urged him not to sell the car.'

Zhangsan BEI I sent someone arrest-PFV

'Zhangsan was arrested by me sending someone to do so.'

The proposal of V-NP-V as a complex verb in fact implies that the control complement in such a sentence does not represent a full CP but, rather, a reduced structure, which is a precursor of Grano's $(2012,2015)$ proposal of a mono-clausal/bi-clausal distinction between control/non-control constructions without resorting to finiteness. 
Second, Y. Huang argued that aspectual markers may occur in both the matrix and the embedded clauses. This counters C.-T. J. Huang's claim about V-NP-V sequence as a complex verb. This is shown below in (37). ${ }^{15}$

(37) Dajie jiao-guo Xiaoming tan-guo gangqin. Elder sister teach-EXP Xiaoming play-EXP piano 'Elder sister taught Xiaoming to play piano.'

(Y. Huang, 1994, p. 29)

Based on these counterexamples, Y. Huang suggested that aspectual markers such as -le and guo can occur with the embedded predicate and not only with the matrix one. ${ }^{16}$

When it comes to the representation of -guo under control, one can find arguments in favor of each side in the literature. There are several studies siding with C.-T. J. Huang on that the experiential marker - guo under control is realized as the matrix aspect: $\mathrm{Li}(1985,1990)$, Cheng (1989), Grano (2012, 2015), among others. On the other hand, siding with Y. Huang are the following studies: Xu (1986), Tang (1988), and Hu et al. (2001), among others.

\subsubsection{Li $(1985,1990)$ vs. Xu (1986)}

\footnotetext{
${ }^{15}$ Sentence like this is considered marginally acceptable by Li (1985). suppletive counterpart of -le, not -guo.

(A) Wo mei you bi ta qu-guo nali.

I NEG PFV pressure him go-EXP there

'I did not pressure him to go there.'
}

${ }^{16}$ Y. Huang also noted that when sentences like (34b) are negated, the aspectual marker you and -guo can be found respectively at the matrix and the embedded level, like that in (A). However, it is unclear why (A) can be a counterexample to C.-T. J. Huang's negation argument since C.-T. J. Huang only suggested that you is the 
In support of C.-T. J. Huang's view of -guo under control instantiating non-local realization of the matrix aspect, $\operatorname{Li}(1985,1990)$ proposed an INFL lowering rule. This lowering rule makes aspectual markers move from main clauses to embedded clauses. According to $\mathrm{Li}$, one piece of evidence for this rule is that there is a collocational constraint between time adverbials such as congqian 'before' and the aspectual marker -guo. Sentences in (38) and (39) illustrate this collocational constraint.

(38) a. Wo congqian qing/gaosu-guo Zhangsan.

I before invite/tell-EXP Zhangsan

'I have invited/told Zhangsan before.'

b. *Wo congqian qing/gaosu Zhangsan.

I before invite/tell Zhangsan

(39) a. Wo congqian gaosu-guo ta [ni lai zher].

I before tell-EXP him you come here

'I told him before that you came here.'

b. Wo congqian gaosu-guo ta [ni lai-guo zher].

I before tell-EXP him you come-EXP here

'I told him before that you had been here.'

c. Wo gaosu ta [ni congqian lai-guo zher].

I tell him you before come-EXP here

'I told him that you have been here before.'

d. *Wo congqian gaosu ta [ni lai-guo zher].

I before tell him you come-EXP here 
In (38) and (39), the grammaticality of each sentence depends on whether congqian and -guo are in a local relation. A sentence is grammatical if congqian and -guo occur in the same clause and ungrammatical otherwise. That is why (38a) and (39a-c) are acceptable whereas (38b) and (39d) are not. However, consider (40).

(40) Wo congqian qing ta [chi-guo fan].

I before invite him eat-EXP meal

'I invited him to eat before.'

In (40), congqian and - guo do not appear to be in a local relation, but the sentence is grammatical. This can be interpreted as evidence that - guo in the embedded clause in (40) in fact is associated with the matrix verb, since congqian and -guo must be in a local relation. With this in mind, it should also be the case that - guo under control in sentences without conqian like (34b) also instantiates non-local realization of the matrix aspect. Moreover, since the syntactic position of -guo has been assumed in the literature to have a direct impact on the interpretive effects, i.e., the actualization of the embedded event, of sentences like (34b), a matrix projection of -guo under Li's INFL lowering rule suggests that - guo only actualizes the matrix event in a control sentence. Thus, Li argued that the following sentences containing qing 'invite' have the same interpretive effects in terms of the matrix and embedded event actualization. That means no matter if -guo occurs with the matrix predicate as in (41a) or with the embedded predicate as in (41b), only the action described by the matrix predicate should be carried out because -guo is underlyingly associated with the matrix predicate. 
(41) a. Wo qing-guo Zhangsan chi fan

I ask-EXP Zhangsan eat meal

'I have invited Zhangsan to eat.'

b. Wo qing Zhangsan chi-guo fan.

I ask Zhangsan eat-EXP meal

'I have invited Zhangsan to eat.'

(Li, 1985, p. 36)

Since embedded - guo, as Li added, only gives the sentence an interpretation that the matrix event is actualized, sentences (42a-b) below should also be grammatical: The information described by the second clause conjuncts (underlined) does not contradict the information conveyed by the first clause conjuncts, which contain-guo under control.

(42) a. Wo quan ta jie-guo yan, keshi ta bu ken jie.

I urge him quit-EXP cigarette but he NEG will quit

'I urged him to quit smoking, but he will not stop.'

b. Wo bi ta chi-guo yao, keshi ta bu ken chi.

I pressure him eat-EXP medicine, but he NEG will eat

'I pressured him to take medicine, but he will not.'

(Li, 1990, p.19) 
However, Xu (1986) proposed an opposite view on the interpretations of such sentences in (42a-b). He argued that there are semantic differences between the instances of - guo in a matrix clause and those of - guo in a control complement. For example:

(43) a. Wo qing-guo ta chi fan, keshi ta mei lai.

I invite-EXP him eat meal but he NEG come

'I invited him to have dinner, but he did not come.'

b. *Wo qing ta chi-guo fan, keshi ta mei lai.

I invite him eat-EXP meal but he NEG come

(Xu, 1986, p. 349)

Xu believed that embedded - guo indicates that the event described by the embedded predicate is actualized. That said, (43b) should be ungrammatical, because its second clause, which expresses a proposition that the embedded event of eating a meal is not actualized, contradicts the first clause.

Backing up Xu's opinion, Tang (1988) also stated that -guo, when occurring in a control complement structure, entails the fact the embedded event has taken place. Hu et al. (2001) reiterated Xu's (1986) argument that -guo at the matrix level and -guo at the embedded level result in different meanings. They described the view of - guo under control being realized nonlocally as "contra the intuition of native speakers."

Thus far, there seems to be a rather general trend that the proponents for a finite/nonfinite distinction in Mandarin argue that - guo under control is associated with the higher matrix clause ("proponent group"), while the opponents for a finite/non-finite distinction argue that - guo 
under control is associated with the local embedded clause ("opponent group"). Furthermore, the syntactic projection is assumed to have an immediate effect on the interpretation of sentences containing -guo under control. The proponent group believes that - guo under control does not entail that the embedded event has occurred, while opponent group believes that - guo under control entails that the embedded event has occurred.

\subsubsection{Grano (2012, 2015)}

Grano $(2012,2015)$ adopted a hybrid perspective to approaching this problem. Essentially, he aligned with the proponent group in the belief that - guo under control is syntactically and semantically associated with the matrix clause, but he sided with the opponent group in a way that there is no need to propose a finite/non-finite distinction to account for the relations between control and non-control constructions in Mandarin. Instead, Grano argued that a monoclausal/biclausal distinction can better explain the differences exhibited by the two constructions; more specifically, EC predicates take $v \mathrm{P}$ complements, and thus, are smaller than a CP, whereas non-control predicates take a full $\mathrm{CP}$ as their complements. Grano's evidence for this claim rests on the argument that - guo is not purely aspectual in meaning but also has a temporal component. This argument is built upon J.-W. Lin's $(2003,2006)$ proposals that -guo, with no exception, expresses relative anteriority despite the aktionsart of its hosting sentence, and part of -guo's semantic contribution in sentences is to place the event time before the evaluation time. In a simplex sentence with -guo, the evaluation time is the speech time, and that is why the event time precedes the speech time in such a sentence, as seen in (10). On the other hand, in complex sentences, - guo places the event time of its hosting subordinate clause before the event time of the matrix clause (or the speech time). With this in mind, consider (44a-b). 
(44) a. Zhangsan shuo Lisi chi-guo faguo cai.

Zhangsan say Lisi eat-EXP France meal

'Zhangsan said that Lisi had tried French food.'

b. Zhangsan qing Lisi chi-guo faguo cai.

Zhangsan invite Lisi eat-EXP France meal

'Zhangsan has invited Lisi to eat French food.'

According to Grano, in sentences like (44a), because of the embedded -guo, the event time of the embedded clause precedes the event time of the matrix clause, which in in this case shows that the event of Lisi eating French food takes place before the event of Zhangsan saying something. This perfectly aligns with J.-W. Lin's $(2003,2006)$ treatment of -guo in subordinated clauses. However, in sentences like (44b), although -guo is also attached to the complement predicate, it does not entail that the event time of the complement predicate occurs before the event time of the matrix predicate. In other words, (44b) does not entail that the event of Lisi eating French food takes place prior to the event of Zhangsan inviting Lisi. This provides evidence that (44b) may be fundamentally different from (44a), and -guo loses its temporal control over the complement predicate in $(44 \mathrm{~b})$ because it belongs to the higher predicate. Some people may argue, as Grano noted, that the reason why such a temporal asymmetry occurs in (44a-b) is because the semantics of the verb qing 'invite' in (44b) suppresses the temporal contribution of the -guo under control. Grano reacted to such an argument by inspecting cross-linguistic data. For example, in English, the form have done denotes a relative past interpretation in sentences; 
nonetheless, under the matrix predicate invite, the form have done triggers ungrammaticality. This is shown in (45).

(45) *John invited Mary to have eaten French food.

Sentence (45) shows that lexical semantics of the matrix verb invite cannot overrule the temporal contribution of an embedded aspectual element.

Based on the fact that -guo in (44a) places the event's topic time before the evaluation time and -guo in (44b) fails to do so, Grano argued that the complement of (44a) is a CP while that of (44b) is a $v \mathrm{P}$. Thus, control sentences are mono-clausal structures, while non-control ones are bi-clausal structures.

Besides this temporal reference argument, Grano also reiterated other two arguments in support of his stance. One is Li's (1990) same-clause constraint exhibited by the time adverbial congqian 'before' with -guo, which is shown in (38)-(40). Grano argued that the contrasting effect exhibited by the clauses with gaosu 'tell' and those with qing 'invite' can be explained by sustaining the generalization that congqian and -guo must occur in the same clause, as well as by regarding sentences like (40) as mono-clausal functional restructuring configurations.

The other argument pointing to Grano's mono-clausal/bi-clausal conclusion is based on C.-T. J. Huang's (1989) negation argument, which has been discussed in (34)-(35). Inspired by this argument, Grano argued that the interaction between negation and embedded aspect can provide compelling evidence for a mono-clausal/bi-clausal proposal. This originates from how negation works in Mandarin: When a sentence with no overt aspectual marking, such as (46a), is negated, a negative marker $b u$ is inserted preverbally (46b); when a sentence with an overt 
aspectual marker - $l e$, such as (47a), is negated, the perfective aspectual marker -le is replaced by $y o u$, and $m e i$ is used as the negative marker instead of $b u(47 b)$.

(46) a. Zhangsan chi meiguo fan.

Zhangsan eat American meal

'Zhangsan eats American food.'

b. Zhangsan bu chi meiguo fan.

Zhangsan NEG eat American meal

'Zhangsan does not eat American food.'

(47) a. Zhangsan chi-le meiguo fan.

Zhangsan eat-PFV American meal

'Zhangsan ate American food.'

b. Zhangsan mei you chi meiguo fan.

Zhangsan NEG PFV eat American meal

'Zhangsan did not eat American food.'

In non-control embedded clauses, the negation patterns shown in (46a-b) and (47a-b) remain. For example, if we embed (47a-b) as non-control complements, the negation does not change. This is illustrated in (48a-b).

(48) a. Lisi gaosu Xiaoming [Zhangsan chi-le meiguo fan].

Lisi tell Xiaoming Zhangsan eat-PFV American meal

'Li told Xiaoming that Zhangsan ate American food.' 
b. Lisi gaosu Xiaoming [Zhangsan mei you chi meiguo fan]. Lisi tell Xiaoming Zhangsan NEG PFV eat American meal 'Lisi told Xiaoming that Zhangsan did not eat American food.'

However, if we insert (47a-b) as control complements, the negation at the complement level becomes ungrammatical, as presented in (49a-b).

(49) a. Lisi bi [Zhangsan chi-le meiguo fan]. Lisi pressure Zhangsan eat-PFV American meal 'Lisi pressured Zhangsan to eat American food.'

b. *Lisi bi [Zhangsan mei you chi meiguo fan]. Lisi pressure Zhangsan NEG PFV eat American meal 'Lisi pressured Zhangsan to eat American food.'

In cases like (49b) where negation and perfective aspect co-occur, the perfective marker you must precede the matrix verb, as shown in (50).

(50) Lisi mei you bi [Zhangsan chi meiguo fan]. Lisi NEG PFV pressure Zhangsan eat American meal 'Lisi did not pressure Zhangsan to eat American food.'

Grano argued such an aspectual position asymmetry arises in (49a-b) and (50) is due to their syntax. In cases such as (49a), the perfective aspectual marker -le is a verbal suffix and therefore 
is attached to the second verb. The projection of such conditions is shown in (51a). In examples such as (49b), the perfective marker becomes you, and since you is an independent word rather than a suffix, it remains high in its base Asp position. The projection is shown in (51b).

(51) a. The AspP in (49a)

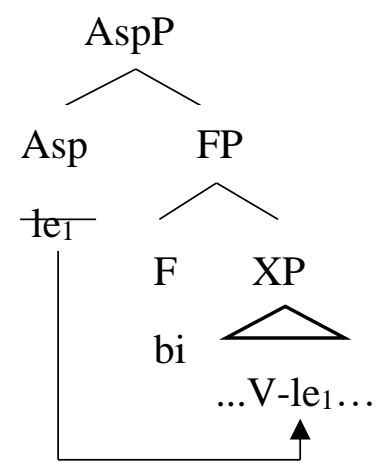

b. The NegP in (49b)

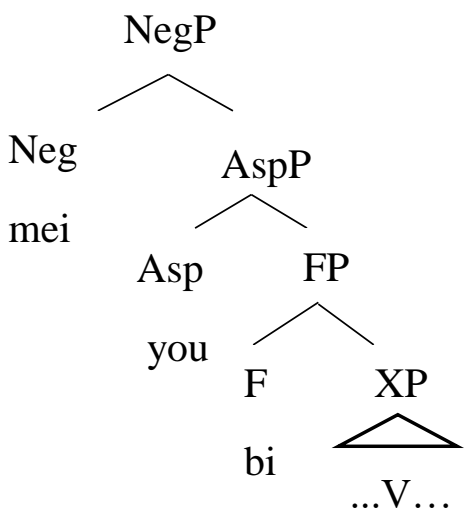

(Grano, 2015, p. 157)

According to Grano, the projections shown in (51a-b) tie to a mono-clausal/bi-clausal argument. Sentence (49a) is mono-clausal and bi 'pressure' is therefore an inflectional-layer functional head, and that is why the complement of bi cannot not have its own projection of Asp that could host the potential embedded occurrence of $y o u$, as in (49b). On the other hand, sentence (48b) is bi-clausal and that is why its lower CP can host the embedded you. ${ }^{17}$

To sum up, as for the status of -guo under control and the interpretations of sentences containing - guo under control, linguists are divided into two groups: Some

\footnotetext{
${ }^{17}$ As Grano (2015, p. 157) noted, an important problem remains: "Where in the structure of the Mandarin clause the projections associated with aspectual markers like -le and -guo are realized" and "how -le and -guo end up as suffixes." His solution to this problem is based on the most popular approaches in the generative grammar, Asp is projected above VP. With the presence of suffixes such as -le and -guo, three proposals come into sight: V-to-Asp movement, PF-lowering of Asp to V, or base-generation of Asp as a suffix on V plus LF raising. Grano favored Gu's (1993) argument that the third proposal can best analyze the syntax of aspectual marking in Mandarin.
} 
believe that -guo under control is owned by the matrix predicate, so the meaning derived from such a structure is that only the matrix event is actualized. On the contrary, other linguists believe that - guo is owned by the embedded predicate, ${ }^{18}$ and therefore the meaning yielded from such a structure is that the embedded event is actualized. That said, it seems that the status of -guo under control is very debatable, and that theoretical analyses fail to convince linguists reach a consensus on this question. This situation creates a need for the use of experimental methods. Encouragingly, there has already been an experimental attempt made regarding the interpretive effects of Mandarin sentences containing - guo under control. In the next subsection, I review this recent study.

\subsection{Grano and Zhang's (2018) Experimental Study}

Since linguists on the theoretical side do not share a unified opinion on the syntactic position of -guo in control complements and the semantic interpretation of sentences containing guo in control complements, and the major disagreement focuses on the question as to whether or not -guo under control entails that the event described by the controlled predicate has happened, Grano and Zhang (2018) conducted an experimental study to examine the extent to which -guo in control complements gives rise to actuality entailments among native speakers of Mandarin.

They selected one Mandarin verb quan 'urge' as the matrix verb, along with three embedded eventive predicates, which were: (a) hui laojia 'return to hometown', (b) qu yiuan 'go to the hospital', and (c) xue kaiche 'learn how to drive'. The matrix verb along with the three eventive predicates constitute the following three sentence frames.

\footnotetext{
${ }^{18}$ For the ease of exposition, I sometimes refer to the predicate under control as the embedded predicate, although it is not the case under a mono-clausal assumption.
} 
(52) a. Zhangsan quan Lisi [hui laojia].

Zhangsan urge Lisi return hometown

'Zhangsan urges Lisi to return to hometown.'

b. Li laoshi quan Xiaohua [qu yiyuan].

Li teacher urge Xiaohua go hospital

'Teacher Li urges Xiaohua to go to the hospital.'

c. Wang jingli quan Xiaoliu [xue kai che].

Wang manager urge Xiaoliu learn drive car

'Manager Wang urges Xiaoliu to learn to drive.'

(Grano \& Zhang, 2018, p. 5)

Besides sentences frames, they constructed three aspectual conditions, which were: (a) guo in the matrix clause, (b) -guo in the embedded clause, and (c) no -guo (no aspectual marking). For example, sentences (53a-c) showcase the items generated by the predicate (a) hui laojiao 'return to hometown', combined with the three aspectual conditions.

\begin{tabular}{l} 
(53) a. Zhangsan quan-guo Lisi hui laojia. [matrix -guo] \\
\hline
\end{tabular} Zhangsan urge-EXP Lisi return hometown

b. Zhangsan quan Lisi hui-guo laojia. [embedded -guo] Zhangsan urge Lisi return-EXP hometown

$\begin{array}{ll}\text { c. Zhangsan quan Lisi hui laojia. [no - guo] } & \end{array}$

Zhangsan urge Lisi return hometown

(Grano \& Zhang, 2018, p. 4) 
Three sentence frames, along with three aspectual conditions, yielded a total of nine sentences. Each of the nine sentences was further investigated based on two contextual conditions:

"Happen" context and "Failed" context. "Happen" context refers to the scenario in which the described embedded event happened, and "Fail" context refers to the situation in which the embedded event did not happen. For example, the sentence generated by sentence frame (a) and aspectual condition (a), shown in (53a), Zhangsan quan-guo Lisi hui laojia, is evaluated based on the two contexts illustrated in (54).

(54) a. 'Happen' context

Zhangsan juede Lisi yinggai hui laojia, danshi Lisi bu xiang hui, Zhangsan think Lisi should return hometown but Lisi NEG want return zuizhong Lisi zhao-zuo-le.

finally Lisi according-do-PFV

'Zhangsan thought Lisi should return to hometown, but Lisi didn't want to. Finally, Lisi did.'

b. 'Fail' context

Zhangsan juede Lisi yinggai hui laojia, danshi Lisi bu xiang hui, Zhangsan think Lisi should return hometown but Lisi NEG want return zuizhong Zhangsan fangqi-le.

finally Zhangsan quit-PFV

'Zhangsan thought Lisi should return to hometown, but Lisi didn't want to. Finally, Zhangsan gave up.'

(Grano \& Zhang, 2018, p. 4) 
The nine sentences, along with either a "Happen" or "Fail" context, yielded a total of 18 items. That indicated that each item consisted of two components: a baseline sentence and a context based on which this baseline sentence was judged. A total of 36 native speakers of Mandarin in Chongqing, China, ${ }^{19}$ participated and rated six items out of the 18 items on a scale of 1-5, 5 being the most acceptable. The results are shown below in Table 1 .

Table 1 Mean Results

\begin{tabular}{lcc}
\hline & Happen & Fail \\
\hline Matrix -guo & 3.72 & 4.47 \\
\hline Embedded -guo & 3.30 & 3.27 \\
\hline No -guo & 4.22 & 4.00 \\
\hline
\end{tabular}

(Grano \& Zhang, 2018, p. 6)

The data, analyzed with a mixed linear model, show that although there is a global aversion toward embedded - gио compared to matrix - gио and zero - guo, all the situations are acceptable to native speakers of Mandarin. Besides, -guo in control complements does not give rise to actuality entailments. In other words, - guo in control complements does not prescribe that the embedded event has happened. According to Grano and Zhang, the results thereby lend support to the non-local analysis of - guo under control, suggesting that there is no significant interpretation difference between matrix - guo and embedded - guo in control constructions.

\footnotetext{
${ }^{19}$ In Chongqing, native speakers of Mandarin use the Southwestern dialect (Li \& Thompson, 1981).
} 
Grano and Zhang's (2018) study contributes to the theoretical debate on -guo in control complements. It elicited judgment from a population, rather than from one, or a few, native speaker consultants. However, since only one object verb, quan 'urge', was tested in the experiment, the question of whether the use of other control verbs will yield different results remains. Besides, the "Fail" context in their experiment, in fact, did not completely "fail"; rather, the actualization of their "Fail" contest could be open to different interpretations. Precisely, the final clause of their "Fail" context, shown in (54b), was that zuizhong Zhangsan fangqi le 'finally Zhangsan (the person who urges, the "urger") gave up', but this did not imply that Lisi (the person who is urged, the "urgee") carried out the embedded action, but only that the "urger" stopped urging. In other words, although the "urger" eventually gave up, the "urgee" could still have carried out the embedded action. That said, more clarified contextual conditions for an experiment of this kind may lead to more robust results. Third, the rating for the no - guo condition in both the "Happen" and "Fail" context in their study, especially in the "Happen" context, created a "myth": Since the rating for the "no -guo/"Happen"” case was most preferred, it seemed that the participant had already exhibited a certain preference for the embedded event actualization before - guo was actually involved. That raises the question of what purpose, if any, -guo does have in control constructions.

In order to understand, in more depth, the question of whether actuality entailments incur with -guo under control, as well as to gain some insight into the other interesting characteristics that have arisen from Grano and Zhang's (2018) data, a more comprehensive study is needed. This study is conducted to serve this purpose. In the next subsection, I articulate the research question and hypothesis of this study. 


\subsection{Research Question and Hypothesis}

The primary question this study examines concerns whether - guo under control gives rise to actuality entailments. Actuality entailments, essentially, refer to instances where the actuality implications of events described by complements are non-cancellable (Bhatt, 1998; Hacquard, 2006).

The bifurcated hypothesis is stated below:

(55) Hypothesis A: Mandarin -guo under control does not give rise to actuality entailments. Hypothesis B: Mandarin -guo under control gives rise to actuality entailments.

The expected experimental results related to the hypothesis are explained in the follows. If -guo under control yields actuality entailments (i.e., the event occurred) in a sentence, then given a "Happen" context specifying that the embedded event is actualized, the use of such a sentence will be acceptable; given a "Fail" context describing that the embedded event did not occur, the use will be unacceptable. If - guo under control does not trigger actuality entailments in a sentence, regardless of the context, the acceptability issue should not be stake, given that random performance is expected.

\section{Chapter 3 Methodology}

\subsection{Participants}

The participants of this study consisted of 260 native speakers of Mandarin, including 69 males and 191 females, from Liaoning, China. The participants' ages ranged from 18 to 50 . They were recruited through convenience sampling. 


\subsection{Research Design}

\subsubsection{Sentence Stimuli}

Control sentence stimuli were constructed. Each sentence stimulus comprised a matrix verb, an embedded verb, and an aspectual condition of - guo. Three aspectual conditions of -guo were included: - guo attached to the matrix verb, - guo attached to the embedded verb, and no guo attached (baseline). The three schematizations in (56) represent all the possible sentence stimulus constructions in this study.

(56) a. No - guo - baseline

$[$ Vmatrix $+[$ Vembedded $]$

b. Matrix -guo

$[$ Vmatrix-guo $+[$ Vembedded $]]$

c. Embedded - guo

$[$ Vmatrix $+[$ Vembedded-guo $]$

\subsubsection{Matrix Verbs}

Both subject control and object control matrix verbs were included. The subject control verb I chose is changshi 'try', and the object control verbs I selected are guli 'encourage' and zuzhi 'oppose'.

\subsubsection{Embedded Verbs}

Three embedded predicates (i.e., a verb and an object) were chosen in combination with the three above matrix verbs respectively. They were: 
(57) a. hua youhua 'do oil painting'

b. xie shi 'write poems'

c. jian Zhangsan 'meet with Zhangsan'
- changshi 'try'

-guli 'encourage'

$-z u z h i$ 'oppose'

\subsubsection{Sentence Frames}

With the matrix verbs and the embedded verbs, the following three sentence frames were constructed.

(58) a. Wo changshi [hua youhua]

I try paint oil painting

'I try doing oil painting.'

b. Wo guli ta [xie shi].

I encourage him write poem

'I encourage him to write poems.'

c. Wo zuzhi ta [jian Zhangsan].

I oppose him meet Zhangsan

'I oppose him meeting with Zhangsan.'

Each sentence frame in (58) was combined with the three aspectual conditions (no - guo, matrix guo, and embedded - guo), yielding three sentences each and resulting in a total of nine sentences. The subject control sentences are illustrated in (59), and the object control sentences are illustrated in (60) and (61). Among these, those in (a) represent no -guo, those in (b) matrix -guo, and those in (c) embedded - guo. 


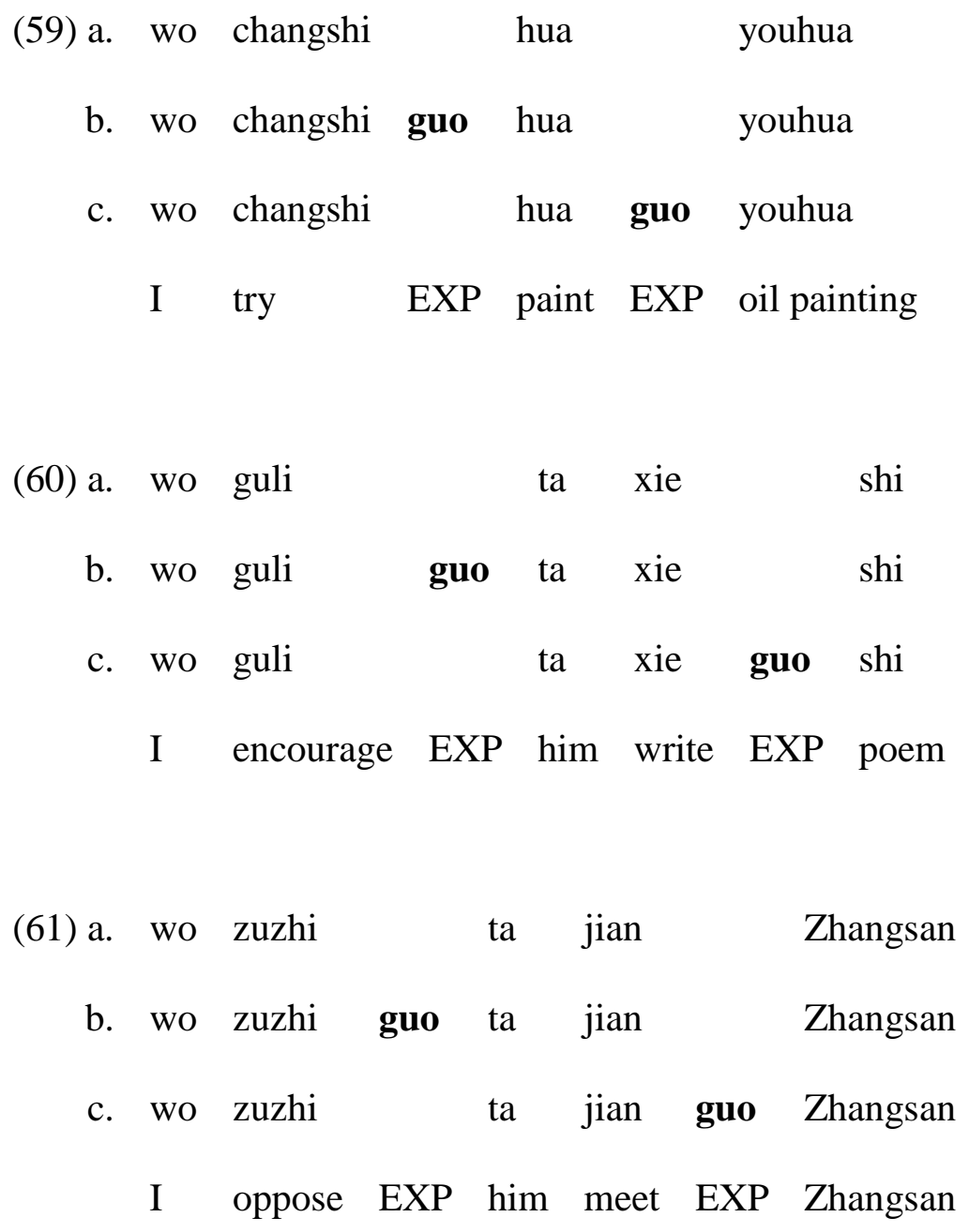

\subsubsection{Contextual Conditions}

Two conditions were constructed for the stimuli, contextualized respectively as "Happen" and "Fail." The "Happen" context refers to a condition in which the event described by the embedded predicate occurred, while the "Fail" context refers to a condition in which such an event did not occur. The nine sentence stimuli in (59-61) were evaluated in the aforementioned contexts. For example, each sentence stimulus containing the verb changshi 'try' in (59) was judged in the contexts outlined in (62). 
(62) a. "Happen" Context

Wo juede wo yinggai hua youhua, tingshuo hennan, danshi zuizhong wo

I think I should paint oil painting hear difficult but finally I haishi hua le.

still paint PFV

'I think I should do oil painting. I heard that it is difficult, but finally I did it.'

b. "Fail" Context

Wo juede wo yinggai hua youhua, tingshuo hennan, suoyi zuizhong wo

I think I should paint oil painting hear difficult so finally I

mei hua.

NEG paint

'I think I should do oil painting. I heard that it is difficult, so finally I did not do it.'

Each sentence stimulus containing the verb guli 'encourage' in (60) was judged in the following two contexts in (63).

(63) a. "Happen" Context

Wo juede ta yingai xie shi, suiran ta bu xiang xie, danshi

I think he should write poem though he NEG want write but zuizhong ta haishi $\underline{x i e}$ le.

finally he still write PFV

'I think he should write poems. He did not want to, but finally he did it.'

b. "Fail" Context 
Wo juede ta yinggai xie shi, keshi ta bu xiang $\underline{x i e}$, suoyi

I think he should write poem but he NEG want write so zuizhong ta mei xie.

finally he NEG write

'I think he should write poems. He did not want to, so finally he did not do it.'

Sentence stimuli containing zuzhi 'oppose' in (61) were assessed based on the contexts in (64).

(64) a. “Happen” Context

Wo juede ta bu yinggai jian Zhangsan, keshi ta xiang jian,

I think he NEG should meet Zhangsan but he want meet suoyi zuizhong ta haishi jian le.

so finally he still meet FPV

'I do not think that he should meet with Zhangsan. He wanted to, so finally he did it.'

b. "Fail" Context

Wo juede ta bu yinggai jian Zhangsan, suiran ta xiang jian, I think hi NEG should meet Zhangsan, though him want meet danshi zuizhong ta mei jian. but finally he NEG meet 'I do not think he should meet with Zhangsan. He wanted to, but finally he did not do it.' 
Nine sentence stimuli, with two contexts each, yielded a total of 18 items. Each potential item was rated by a given participant on a scale of 1-5, 1 being the least acceptable and 5 being the most acceptable. In the evaluation process, the acceptability of each sentence stimulus crucially depended on whether the embedded event actualization expressed by the stimulus fit the given context. A sentence would be considered acceptable if it fit the context, while it would be considered unacceptable if it did not.

\subsection{Data Collection Methods}

All 18 items were programmed into ProProfs, a knowledge management software, under a quiz mode. For each test taken by a participant, the system randomly selected four items out of the 18 items, in addition to another six fillers which were of equal complexity with the test items. That means, in one test each participant rated a total of 10 items (four test items and six fillers). Each item was presented in front of the participant on an electronic screen one at a time in a pseudorandomized order.

\subsection{Specific Procedures for Experimenting}

The test was implemented in the following manner. First, demographic information was collected from the participants, including their name, gender, age, and province of origin. Then, the participants were given the test instructions, including rating procedures, rating scale interpretations, and a demonstration of a sample rating. After the participants confirmed that they understood the entire procedures, the test began. During the rating process, the rating instructions were present by the side of each item that appeared. After the participants answered all the questions, they were thanked by the researcher. 


\section{Chapter 4 Results}

\subsection{Valid Data}

All the ratings were z-transformed by participant and analyzed with a mixed-effects regression model implemented in the lme4 package for R (Bates, Maechler, Bolker, \& Walker, 2015). As mentioned in 3.1, a total of 260 participants were initially recruited for the experiment; subsequently, 260 responses to the test were received. Nonetheless, the z-transformation excluded 11 test responses, the standard deviations of which were 0 and therefore could not be analyzed in z-score normalization. As a result, 249 test responses were valid; since each test response contained four items (out of the 18 items), a sum of 996 observations were obtained.

\subsection{Main Results}

The box plots which demonstrate the rating for each verb by embedding and context are shown below in Figure 2.

Figure 2 Rating by Embedding and Context
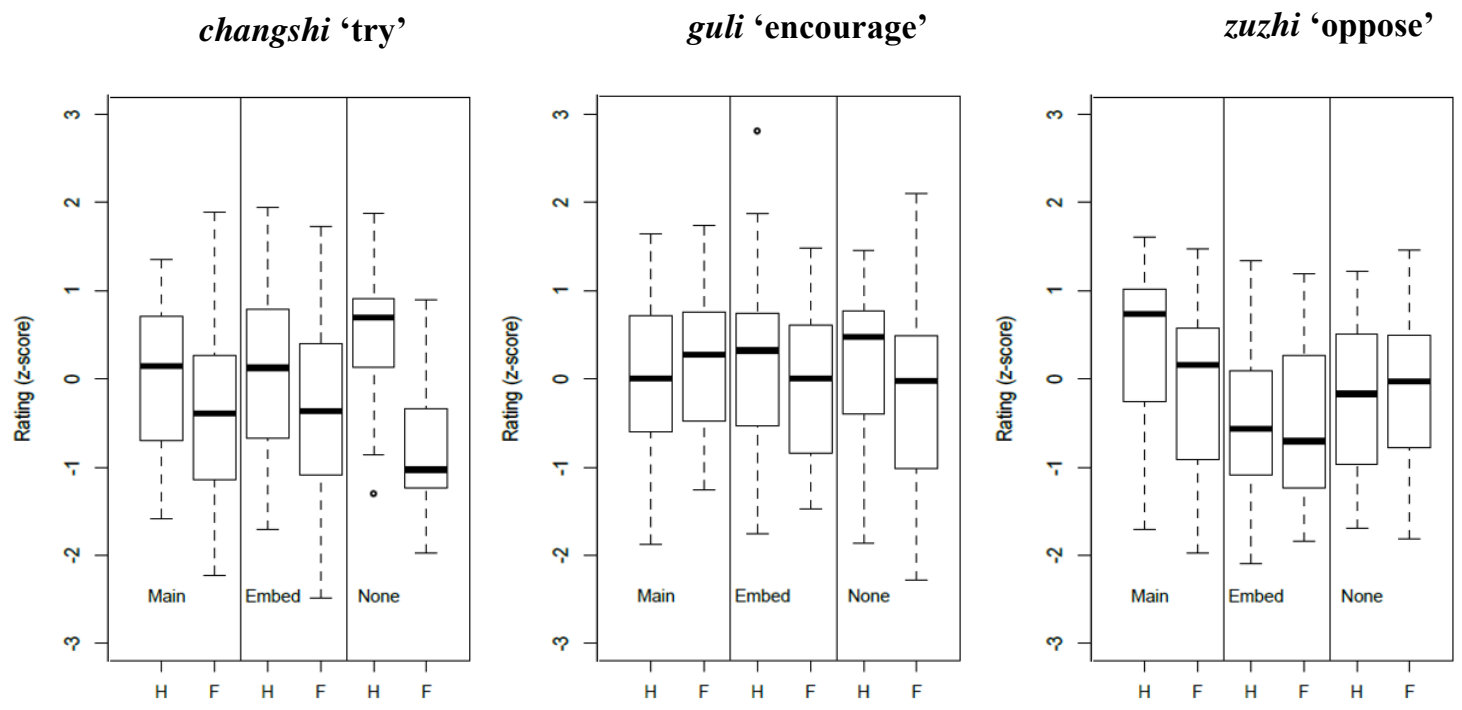

$$
\text { Context ('H' = Happen, 'F' = Fail) }
$$


The fixed-effects in the model is shown in Table 2.

Table 2 Fixed-Effects Model ${ }^{20}$

$\begin{array}{lrrr} & \text { Beta } & \text { Std. Error } & \mathrm{t} \text { value } \\ \text { (intercept) }^{21} & 0.5252 & 0.1188 & 4.378 \\ \text { matrix } & -0.4848 & 0.1696 & -2.858 \\ \text { emb } & -0.4717 & 0.1592 & -2.963 \\ \text { as.factor(fail)1 } & -1.2714 & 0.1665 & -7.638 \\ \text { guli } & -0.3291 & 0.1721 & -1.913 \\ \text { zuzhi } & -0.6696 & 0.1656 & -4.042 \\ \text { matrix:as.factor(fail)1 } & 0.8721 & 0.2378 & 3.667 \\ \text { emb:as.factor(fail)1 } & 0.9027 & 0.2270 & 3.976 \\ \text { matrix:guli } & 0.2689 & 0.2432 & 1.106 \\ \text { matrix:zuzhi } & 1.0221 & 0.2349 & 4.352 \\ \text { emb:guli } & 0.4221 & 0.2296 & 1.838 \\ \text { emb:zuzhi } & 0.1367 & 0.2247 & 0.608 \\ \text { as.factor(fail)1:guli } & 0.9217 & 0.2362 & 3.902 \\ \text { as.factor(fail)1:zuzhi } & 1.3255 & 0.2254 & 5.882 \\ \text { matrix:as.factor(fail)1:guli } & -0.3180 & 0.3384 & -0.940 \\ \text { matrix:as.factor(fail)1:zuzhi } & -1.3307 & 0.3245 & -4.100 \\ \text { emb:as.factor(fail)1:guli } & -0.8045 & 0.3244 & -2.480 \\ \text { emb:as.factor(fail)1:zuzhi } & -1.0003 & 0.3161 & -3.164\end{array}$

For the verb changshi 'try', based on the empirical plots in Figure 2 and the $\beta$ s in Table 2, there is a sizable preference contrast between the "Happen" and "Fail" context in the no -guo condition. This suggests that when the matrix verb changshi 'try', in its bare form, occurs in a control sentence, the actualization of its embedded event seems most apparent. When changshi 'try' is marked for - guo at the matrix or embedded level, the actualization seems to become less apparent. That is, the involvement of -guo seems to create some "uncertainty" for the

\footnotetext{
${ }^{20}$ In Table 2, beta, or $\beta$, is the effect size in units of standard deviation. The standard error (Std. Error) is a measure of uncertainty corrected for sample size. The $t$ statistic represents the effect size $\beta$ in units of standard error: it is a measure of effect size corrected for the uncertainty associated with the sample size. T values greater than roughly 2 , or less than roughly -2 , are generally considered statistically significant.

${ }^{21}$ The intercept, or the baseline condition, refers to the item that contains changshi "try'/no -guo/the "Happen" context.
} 
actualization judgment. ${ }^{22}$ This difference, exhibited by the absence and the presence of -guo, indicates that in the case of changshi 'try', it is the matrix verb changshi 'try' that contributes to the actualization of its embedded event, not -guo. That is to say, -guo under control does not give rise to actuality entailments.

For the verb guli 'encourage' in the no -guo condition, there is a preference for the "Happen" context over the "Fail" context. This suggests that when guli 'encourage' occurs as the matrix verb in a control construction, with no -guo aspectual marking, the actualization of its embedded event is rather apparent. This resembles the pattern observed from the verb changshi 'try', although the effect here is not as large as that for changshi 'try'. Besides, similar to changshi 'try', when an embedded -guo occurs, the preference contrast between the "Happen" and "Fail" context shrinks, but the shrinking effect is also much smaller compared to that for changshi 'try'. ${ }^{23}$ Besides, for the verb guli 'encourage', the z-transformed ratings for the no -guo and the embedded - guo condition, in both contexts, do not exhibit much of a variation. That is, in control constructions containing guli 'encourage' as the matrix verb, the actualization of the embedded event does not appear to depend on the presence of -guo. Crucially, when -guo is present at the embedded level, the "Fail" context is slightly disfavored compared to the "Happen" context; however, such a "Happen" vs. "Fail" asymmetry exists independently of guo, i.e., in the no -guo condition. This shows that there is no evidence that embedded - guo triggers actuality entailments in the case of guli 'encourage'.

\footnotetext{
${ }^{22}$ This may suggest that although -guo is generally considered to have a default function of making an event perfectivized, the presence of - guo is not favored in this kind of actualization judgement experiment. That is why the participants have shown a strong preference/dis-preference for the items without -guo, and this polarized preference effect is somewhat neutralized with the involvement of - guo.

${ }^{23}$ This consideration may seem, to some extent, counterintuitive since it does not appear to follow the logical rules of how an event should come along in an actual world: Just because the subject encouraged the object to do something does not mean that the object did it. However, as shown, the participants have demonstrated a rather consistent "desire" for the actualization of the embedded event: When an event is encouraged to occur, it is likely to be perceived to occur or have occurred.
} 
For the verb zuzhi 'oppose', both the "Happen" and "Fail" contexts are disfavored in the no -guo condition, with the "Fail" one being slightly preferred. When the matrix -guo is involved, there is a liking improvement for both the "Happen" and "Fail" context, especially for the "Happen" context. Compared to the no - guo condition, adding an embedded -guo significantly reduces the rating, ${ }^{24}$ with the "Fail" context receiving a slightly lower rating than the "Happen" context. The marginal preference contrast between these two contexts, again, indicates no evidence for -guo under control to yield actuality entailments.

To sum up, the results for the three verbs tested in this experiment, changshi 'try', guli 'encourage', and zuzhi 'oppose', do not suggest any positive evidence that - guo under control gives rise to actuality entailments. In the next chapter, I discuss how these results inform us about the status of -guo under control, as well as a few other interesting characteristics observed from the results.

\section{Chapter 5 Discussion}

\subsection{The Status of - guo Under Control}

In a nutshell, on the status of -guo under control, this experiment fails to find evidence that -guo under control gives rise to actuality entailments. In other words, when - guo occurs under control, it does not entail the fact that the embedded event has been actualized. This aligns with Grano and Zhang's (2018) primary experimental findings.

However, the data suggest that the theoretical picture of - guo under control may not be as clear-cut as previously assumed. First, based on the results of this study and the previous

\footnotetext{
${ }^{24}$ This rating pattern, in the case of zuzhi 'oppose', is reminiscent of Grano and Zhang's (2018) findings regarding the acceptability of each aspectual condition for the matrix verb quan 'urge': Embedded -guo is globally less accepted than matrix - guo and no - guo. However, the other two verbs tested in this experiment do not exhibit the same trend.
} 
theoretical arguments, it is not clear why -guo in the complement of an intensional verb (e.g., guli 'encourage' in this experiment) should entail or presuppose the actualization of the complement event in the first place (Grano, 2013; pace Xu, 1986; Tang, 1988; Y. Huang, 1994; Hu et al., 2001). That is, since - guo under control is in the scope of an intensional verb, it should not be expected to function the same way as it does in a simple clause. This can be analogized to English examples shown in (65).

(65) a. John has completed his homework.

b. I encouraged John to have completed his homework (by the time I came back).

In (65a), the perfective aspect, in the form of have done, entails that John is done with his homework; however, the same aspect in the complement of the intensional verb encourage in (65b) does not entail the same information. That said, based on the results of this study, Mandarin - guo under control may function similarly as English have done under control. Mandarin examples in (66) are set to compare with those in (65).

(66) a. Zhangsan xie-guo whi.
Zhangsan write-EXP poem
'Zhangsan has written poems.'
b. Wo guli $\quad$ Zhangsan xie-guo shi.
I encourage Zhangsan write-EXP poem
'I encouraged Zhangsan to write poems.'


In (66a), due to the presence of -guo, the event of Zhangsan writing poems is unquestionably actualized. However, in (66b), since -guo is in the scope of the intensional verb guli 'encourage', it is not clear that it should be triggering actuality entailments.

Besides, as Grano (2013) points out, even for non-control instances with an embedded guo non-controversially projected at the embedded level, which, given Xu's (1986) and others' assumptions, should indicate that the event is actualized, they can in fact be followed by a clause that denies the actualization of such an event. For example:

Zhangsan tingshuo Lisi chi-guo liulian, keshi shishishang Lisi conglai
Zhangsan hear Lisi eat-EXP durian but infact
mei chi-guo liulian.
NEG eat-EXP durian

'Zhangsan heard that Lisi has eaten durian, but in fact Lisi has never eaten durian.'

(Grano, 2013, p. 37)

\begin{abstract}
All of the above, therefore, confirms that the aspectual function of -guo under a matrix verb (control or non-control) may not be exhaustively fulfilled as it is when occurring in a simple clause.
\end{abstract}

Although the results in this thesis show that there is no evidence that - guo under control triggers actuality entailments (pace Xu, 1986; Tang, 1988; Y. Huang, 1994; Hu et al., 2001), nonetheless, the matrix analysis of -guo (cf. Li, 1985, 1990; C.-T. J. Huang, 1989; Cheng, 1989; Grano, 2012, 2015; Grano \& Zhang 2018) does not remain as our only option. In other words, although the results make the matrix analysis of -guo seem more appealing, another possibility 
cannot be ruled out: That Mandarin - guo under control is indeed projected at the embedded level, but since it is in the scope of a matrix verb, its function may not be exhaustively realized. This view can be further supported by the fact that when the Mandarin durative aspectual marker -zhe is under control, it is realized locally as the embedded aspect. For example:

(68) a. Wo rang/bi/quan Zhangsan fu-zhe Lisi.

I let/pressure/urge Zhangsan hold-DUR Lisi.

'I let/pressured/urged Zhangsan to support Lisi with his arms.'

b. Wo rang/bi/quan-zhe Zhangsan fu Lisi.

I let/pressure/urge-DUR Zhangsan hold Lisi

In (68a), the durative marker -zhe occurs with the embedded verb $f u$ 'hold', giving the verb $f u$ a durative reading. Crucially, -zhe can only be construed with the embedded verb in this case, and it becomes infelicitous when construed with the matrix verb, as shown in (68b).

Based on these examples, an embedded analysis of - guo under control also seems feasible: Similar to English [cf. (65)], Mandarin aspectual markers under control are syntactically projected at the embedded level, but the interpretive effects regarding the embedded event actualization are variable.

The implication of this variability, in relation to the debate about control and non-control structures, is that interpretive effects may not be good evidence to rely on when arguing for possible structural differences between control and non-control constructions in Mandarin. 


\subsection{Other Considerations}

A few other interesting observations also follow from the results. First, the interpretive judgement of a control sentence varies across different matrix verbs, and the variations are rather large. In this experiment, the three matrix verbs, changshi 'try', guli 'encourage', and zuzhi 'oppose', have received very different ratings in terms of various aspectual conditions of - guo and contextual conditions. For example, with no -guo, ratings for the verb changshi 'try' and the verb guli 'encourage' between the two contexts show similar patterns, but those for the verb zuzhi 'oppose' show a slightly reversed pattern. Besides, although guli 'encourage' and zuzhi 'oppose' both are object control verbs, with an embedded -guo, guli 'encourage' has received considerably higher ratings than zuzhi 'oppose'. Considering the other object control verb quan 'urge' used in Grano and Zhang's (2018) study, it seems that matrix verb change affects the interpretive judgment of a control sentence significantly.

Second, interestingly, in the case of changshi 'try' and guli 'encourage', items with no guo have received rather polarized ratings between the "Happen" and the "Fail" context. This does not seem to fit the conventional theoretical assumptions for bare control constructions, particularly for the object control constructions: The semantic content of a matrix verb should not prescribe its embedded event actualization, because such an actualization is not determined by the subject of the matrix verb, but rather, the object. However, as the results indicate, the participants show a strong "expectation" for the actualization of the embedded event in a control sentence. This furthermore suggests that when it comes to an interpretive judgement test of this kind, factors such as the participant's world knowledge, life experience, and personal expectation, etc., may be inevitably involved. This tendency can also be seen from Grano and 
Zhang's (2018) study, in which, for the matrix verb quan 'urge', the no -guo condition received much higher ratings compared to the matrix -guo condition and the embedded - guo condition.

Third, this study is conducted in a different geographic region than Grano and Zhang's (2018) study, and yet both studies have obtained similar results. This suggests that dialectal difference may not be a fundamental variable affecting the interpretation of control sentences.

\subsection{Limitations and Future Directions}

This study finds no positive evidence that - guo under control gives rise to actuality entailments, but more research is needed to add on and potentially strengthen this finding. In this experiment, only the experiential marker -guo is tested. It would be interesting to see whether, under the same circumstances, an aspectual marker change, e.g., from -guo to the perfective marker-le, will affect the results.

This study does not take external factors, such as the participant's age and gender, as its primary considerations. Future research can control these variables in a stricter manner.

The task of this experiment may be somewhat complex in nature, so although the test instructions were present beside each test item in the course of the experiment, the task might still have created some challenge on the participant's part. Future research may consider an alternative task to investigate questions considered in this thesis.

\section{Chapter 6 Conclusion}

This thesis explores the status of -guo under control in Mandarin; specifically, whether guo under control gives rise to actuality entailments. The experimental results do not provide evidence that it does. Moreover, this study shows that the issue of -guo under control may not be 
as straightforward as previously assumed. Specifically, although - guo under control does not concern entailments, the possibility of - guo under control to be associated with the embedded verb is not ruled out. This is because when -guo is present in the complement of a higher verb, its function may, though not necessarily, be compromised due to this verb. Furthermore, the results indicate that interpretive effects with respect to event actualization may not be an efficacious piece of evidence to contribute to the existing debate about Mandarin control and non-control constructions in the literature, since given various circumstances, the interpretive effects of control sentences do not tend to be consistent. 


\section{References}

Bates, D., Maechler, M., Bolker, B., \& Walker, S. (2015). Fitting linear mixed-effects models using lme4. Journal of Statistical Software, 67(1), 1-48.

Bhatt, R. (1999). Covert modality in non-finite contexts (Doctoral dissertation). Retrieved from ProQuest Dissertations \& Theses Global. (304517430)

Bresnan, J. (1982). Control and complementation. Linguistic Inquiry, 13(3), 343-434.

Chan, M. (1980). Temporal reference in Mandarin Chinese: An analytical-semantic approach to the study of the morphemes le, zai, zhe, and ne. Journal of the Chinese Language Teachers Association, 15(3), 33-79.

Chao, Y. R. (1968). A grammar of spoken Chinese. Berkeley, CA: University of California Press

Cheng, L.-S. L. (1989). Aspectual licensing of pro in Mandarin Chinese. Unpublished manuscript, Department of Linguistics and Philosophy, Massachusetts Institute of Technology, Cambridge, MA.

Chomsky, N. (1981). Lectures on government and binding. Dordrecht, The Netherlands: Foris

Dahl, Ö. (1985). Tense and aspect systems. New York, NY: Basil Blackwell.

Ernst, T. (1994). Functional categories and the Chinese Infl. Linguistics, 32(2), 191-212.

Franks, S., \& Hornstein, N. (1992). Secondary predication in Russian and proper government of PRO. In R. K. Larson, S. Iatridou, U. Lahiri \& J. Higginbotham (Eds.), Control and grammar (pp. 1-50). New York, NY: Springer.

Gajewski, J. R. (2005). Neg -raising: Polarity and presupposition (Doctoral dissertation). Retrieved from ProQuest Dissertations \& Theses Global. (305368096)

Grano, T. (2012). Control and restructuring at the syntax-semantics interface (Doctoral dissertation). Retrieved from ProQuest Dissertations \& Theses Global. (304517430) 
Grano, T. (2013). Control without finiteness contrasts: PRO, aspect, and complementation size in Mandarin Chinese. Unpublished manuscript, Department of Linguistics, Indiana University, Bloomington, IN.

Grano, T. (2015). Control and restructuring. Oxford, UK: Oxford University Press.

Grano, T. (2017). Finiteness contrasts without Tense? A view from Mandarin Chinese. Journal of East Asian Linguistics, 26(3), 259-299.

Grano, T. (2018). Getting the progressive under control: Mandarin vs. English. Paper presented at the 30th North American Conference on Chinese Linguistics, The Ohio State University, Columbus, $\mathrm{OH}$.

Grano, T., \& Zhang, Y. (2018). Getting aspectual -guo under control in Mandarin Chinese: An experimental investigation. Paper presented at the 30th North American Conference on Chinese Linguistics, The Ohio State University, Columbus, OH.

Gu, Y. (1993). Aspect licensing and verb movement in Mandarin Chinese. Chinese University of Hong Kong papers in linguistics, 4, 68-87.

Hacquard, V. (2006). Aspects of modality (Doctoral dissertation). Retrieved from ProQuest Dissertations \& Theses Global. (304948526)

Hornstein, N. (1999). Movement and control. Linguistic Inquiry, 30(1), 69-96.

Hu, J., Pan, H., \& Xu, L. (2001). Is there a finite vs. nonfinite distinction in Chinese? Linguistics, 39(6), 1117-1148.

Huang, C.-T. J. (1982). Logical relations in Chinese and the theory of grammar (Doctoral dissertation). Retrieved from ProQuest Dissertations \& Theses Global. (303264340) 
Huang, C.-T. J. (1989). Pro-drop in Chinese: A generalized control theory. In O. Jaeggli \& K. Safir (Eds.), The null subject parameter (pp. 185-214). Dordrecht, The Netherlands: Kluwer Academic Publishers.

Huang, N. (2015). On syntactic tense in Mandarin Chinese. Paper presented at the 27th North American Conference on Chinese Linguistics, University of California, Los Angeles (Vol. 2, pp. 406-423).

Huang, N. (2018). Control complements in Mandarin Chinese: Implications for restructuring and the Chinese finiteness debate. Journal of East Asian Linguistics, 27(4), 347-376.

Huang, Y. (1994). The syntax and pragmatics of anaphora: A study with special reference to Chinese. Cambridge, UK: Cambridge University Press.

Klein, W. (1994). Time in language. London: Routledge.

Klein, W., Li, P., \& Hendriks, H. (2000). Aspect and assertion in Mandarin Chinese. Natural Language \& Linguistic Theory, 18(4), 723-770.

Kuno, S. (1974). A note on subject raising. Linguistic Inquiry, 5(1), 137-144.

Landau, I. (1999). Elements of control (Unpublished doctoral dissertation). Massachusetts Institute of Technology, Cambridge, MA.

Landau, I. (2000). Elements of control: Structure and meaning in infinitival constructions. Dordrecht, The Netherlands: Kluwer Academic Publishers.

Law, P., \& Ndayiragije, J. (2017). Syntactic tense from a comparative syntax perspective. Linguistic Inquiry, 48(4), 679-696.

Li, C., \& Thompson, S. (1981). Mandarin Chinese: A functional reference grammar. Berkeley, CA: University of California Press. 
Li, M. (1985). Reduction and anaphoric relations in Chinese. Ann Arbor, MI: University Microfilms Internationals.

Li, Y.-H. A. (1985). Abstract case in Chinese (Doctoral dissertation). Retrieved from ProQuest Dissertations \& Theses Global. (303387509)

Li, Y.-H. A. (1990). Order and constituency in Mandarin Chinese. Dordrecht: Kluwer Academic Publishers.

Lin, J.-W. (2003). Temporal reference in Mandarin Chinese. Journal of East Asian Linguistics, 12(3), 259-311.

Lin, J.-W. (2006). Time in a language without tense: The case of Chinese. Journal of Semantics, $23(1), 1-53$.

Lin, J.-W. (2010). A tenseless analysis of Mandarin Chinese revisited: A response to Sybesma 2007. Linguistic Inquiry, 41(2), 305-329.

Lin, T.-H. J. (2011). Finiteness of clauses and raising of arguments in Mandarin Chinese. Syntax, 14(1), 48-73.

Lin, T.-H. J. (2012). Multiple-modal constructions in Mandarin Chinese and their finiteness properties. Journal of Linguistics, 48(1), 151-186.

Lin, T.-H. J. (2015). Tense in Mandarin Chinese sentences. Syntax, 18(3), 320-342.

Noël, D. (2002). Believe-type matrix verbs and their complements: Corpus-based investigations of their functions in discourse (Doctoral dissertation). Retrieved from ProQuest Dissertations \& Theses Global. (305220787)

Simpson, A., \& Wu, Z. (2002). From D to T-Determiner incorporation and the creation of tense. Journal of East Asian Linguistics, 11(2), 169-209.

Smith, C. S. (1991). The parameter of aspect. Dordrecht, The Netherlands: Springer. 
Smith, C. S. (1994). Aspectual viewpoint and situation type in Mandarin Chinese. Journal of East Asian Linguistics, 3(2), 107-146.

Smith, C. S., \& Erbaugh, M. S. (2005). Temporal interpretation in Mandarin Chinese. Linguistics, 43(4), 713-756.

Soh, H. L. (2014). Aspect. In C.-T. J. Huang, Y.-H. A. Li \& A. Simpson (Eds.), The handbook of Chinese linguistics (pp.126-155). West Sussex, UK: John Wiley \& Sons, Inc.

Soh, H. L., \& Gao, M. I. (2007). It's over: Verbal -le in Mandarin Chinese. In N. Hedberg \& R. Zacharski (Eds.), The grammar pragmatics interface: Essays in honor of Jeanette $K$. Gundel (pp. 91-110). Amsterdam, The Netherlands: John Benjamins Publishing Company.

Soh, H. L., \& Kuo, J.-Y. C. (2005). Perfective aspect and accomplishment situations in Mandarin Chinese. In H. J. Verkuyl, H. de Swart \& A. van Hout (Eds.), Perspectives on aspect (pp. 199-216). Dordrecht, The Netherlands: Springer.

Stiebels, B. (2007). Towards a typology of complement control. In B. Stiebels (Ed.), ZAS papers in linguistics (Vol. 47, pp. 1-57). Berlin, Germany: Leibniz-Zentrum Allgemeine Sprachwissenschaft.

Sun, H. (2014). Temporal construals of bare predicates in Mandarin Chinese. Utrecht, The Netherlands: The Netherlands Graduate School of Linguistics.

Sybesma, R. (2007). Whether we tense-agree overtly or not. Linguistic Inquiry, 38(3), 580-587.

Tang, C.-C. J. (1990). Chinese phrase structure and the extended $X^{\prime}$-theory (Doctoral dissertation). Retrieved from ProQuest Dissertations \& Theses Global. (304517430)

Tang, T.-C. (2000). Finite and nonfinite clauses in Chinese. Language and Linguistics, 1(1), 191214. 
Tang, T. (1988). Hanyu cifa jufa lunji [Studies on Chinese morphology and syntax]. Taiwan: Taiwan xuesheng shuju.

Tsai, W.-T. D. (2008). Tense anchoring in Chinese. Lingua, 118(5), 675-686.

Tsang, C. L. (1981). A semantic study of modal auxiliary verbs in Chinese (Doctoral dissertation). Retrieved from ProQuest Dissertations \& Theses Global. (303174087)

Xu, L. (1986). Towards a lexical-thematic theory of control. The Linguistic Review, 5(4), 345376.

Yang, S. (2011). The parameter of temporal endpoint and the basic function of -le. Journal of East Asian Linguistics, 20(4), 383-415.

Zhang, N. N. (2016). Identifying Chinese dependent clauses in the forms of subjects. Journal of East Asian Linguistics, 25(3), 275-311. 